\title{
On the vertical distribution of smoke in the Amazonian atmosphere during the dry season
}

\author{
Franco Marenco ${ }^{1}$, Ben Johnson ${ }^{2}$, Justin M. Langridge ${ }^{3}$, Jane Mulcahy ${ }^{4}$, Angela Benedetti ${ }^{5}$, Samuel Remy $^{6}$, \\ Luke Jones $^{5}$, Kate Szpek ${ }^{3}$, Jim Haywood ${ }^{2,7}$, Karla Longo ${ }^{8}$, and Paulo Artaxo ${ }^{9}$ \\ ${ }^{1}$ Satellite Applications, Met Office, Exeter, UK \\ ${ }^{2}$ Earth System and Mitigation Science, Met Office Hadley Centre, Exeter, UK \\ ${ }^{3}$ Observational Based Research, Met Office, Exeter, UK \\ ${ }^{4}$ Earth System Core Development Group, Met Office Hadley Centre, Exeter, UK \\ ${ }^{5}$ European Centre for Medium-range Weather Forecasts, Reading, UK \\ ${ }^{6}$ Laboratoire de Météorologie Dynamique, UPMC/CNRS, Paris, France \\ ${ }^{7}$ College of Engineering, Maths and Physical Sciences, University of Exeter, Exeter, UK \\ ${ }^{8}$ Instituto Nacional de Pesquisas Espaciais, São José dos Campos, Brazil \\ ${ }^{9}$ Institute of Physics, University of São Paulo, São Paulo, Brazil \\ Correspondence to: Franco Marenco (franco.marenco@metoffice.gov.uk)
}

Received: 23 October 2015 - Published in Atmos. Chem. Phys. Discuss.: 12 November 2015

Revised: 28 January 2016 - Accepted: 7 February 2016 - Published: 25 February 2016

\begin{abstract}
Lidar observations of smoke aerosols have been analysed from six flights of the Facility for Airborne Atmospheric Measurements BAe-146 research aircraft over Brazil during the biomass burning season (September 2012). A large aerosol optical depth (AOD) was observed, typically ranging $0.4-0.9$, along with a typical aerosol extinction coefficient of $100-400 \mathrm{Mm}^{-1}$. The data highlight the persistent and widespread nature of the Amazonian haze, which had a consistent vertical structure, observed over a large distance $(\sim 2200 \mathrm{~km})$ during a period of 14 days. Aerosols were found near the surface; but the larger aerosol load was typically found in elevated layers that extended from 1-1.5 to 4$6 \mathrm{~km}$. The measurements have been compared to model predictions with the Met Office Unified Model (MetUM) and the ECMWF-MACC model. The MetUM generally reproduced the vertical structure of the Amazonian haze observed with the lidar. The ECMWF-MACC model was also able to reproduce the general features of smoke plumes albeit with a small overestimation of the AOD. The models did not always capture localised features such as (i) smoke plumes originating from individual fires, and (ii) aerosols in the vicinity of clouds. In both these circumstances, peak extinction coefficients of the order of $1000-1500 \mathrm{Mm}^{-1}$ and AODs as large as 1-1.8 were encountered, but these features were either un-
\end{abstract}

derestimated or not captured in the model predictions. Smoke injection heights derived from the Global Fire Assimilation System (GFAS) for the region are compatible with the general height of the aerosol layers.

\section{Introduction}

Biomass burning is the second largest source of anthropogenic aerosols globally (Stocker et al., 2013), and South America features as one of the major source regions. In Southern Amazonia, fire is often used for deforestation and for the preparation of agricultural fields and pasture (Brito et al., 2014). The dry season spans from July to October every year, and controls the timing of the intensive burning of the vegetation. Intense precipitation can still occur in this season, due to the increase of convective available potential energy (CAPE) and moisture, associated with the Monsoon circulation (Gonçalves et al., 2015). The rate of biomass burning in the Brazilian rainforest varies from year to year and is affected by meteorological conditions as well as social factors (Kaufman et al., 1998).

The high loadings of biomass burning aerosols, with different degrees of ageing, can affect the regional weather and 
climate (Sena et al., 2013; Rizzo et al., 2013). Episodes of poor air quality and low visibility are frequent, and the aerosol loadings affect the radiation budget and the cloud microphysics (Kaufman et al., 1998). Moreover, the radiative balance of the region is also affected by changes in the surface albedo caused by burning of the vegetation. The latter has an impact well beyond the burning season, as it affects the regional surface energy budget all year round, and has an impact on convection, cloud formation and precipitation (Sena et al., 2013).

The modified ratio of direct to diffuse radiation, and the changes in meteorology, in turn will affect the photosynthetically active radiation flux and the carbon cycle (Mercado et al., 2009). Given that Southern Amazonia is the Earth's largest hydrological basin, the largest carbon sink, and the largest tropical rainforest, the changes in the regional atmosphere and biosphere introduced by biomass burning can have a relevant impact at the global scale. A detailed review of the literature on biomass burning emissions can be found in Koppmann et al. (2005) and Reid et al. (2005b, a).

The large amount of heat released by forest fires can generate strong updrafts and deep convection in their vicinity, rapidly transporting aerosols to upper layers (Freitas et al., 2007; Labonne et al., 2007; Sofiev et al., 2012), followed by long-range transport (Kaufman et al., 1998). Aerosols can be transported for thousands of kilometres, and as they travel they are modified through ageing processes (Hobbs et al., 1997; Kaufman et al., 1998; Fiebig et al., 2003; Vakkari et al., 2014). The composition of biomass burning aerosols is dominated by fine carbonaceous particles (organics and black carbon; see Brito et al., 2014), and in the first 2 hours after emission aerosol scattering can increase up to a factor of six due to photochemistry and secondary particle formation; this is particularly the case for smouldering fires (Vakkari et al., 2014). Particle hygroscopicity and the concentration of CCN are also enhanced during ageing (Abel et al., 2003).

Further downwind, these aerosols continue to exert an impact on cloud formation, convection, and precipitation patterns (Andreae et al., 2004; Koren et al., 2008). Gonçalves et al. (2015) indicates two opposite mechanisms by which biomass burning aerosols affect clouds and precipitation: (i) in a stable atmosphere, for a given liquid water content the formation of a larger number of smaller cloud droplet induces warm rain suppression; and (ii) in an unstable atmosphere, the aerosols enhance precipitation and favour the formation of larger and long-lived cells (convective cloud invigoration). Moreover, Seifert et al. (2015) have observed an increased ice formation efficiency for clouds in the dry season, and a coincidence with the seasonal aerosol cycle.

Knowledge of the vertical structure of the Southern Amazonia smoke layer is key to understanding and assessing the aerosol-cloud interactions (Baars et al., 2012). Textor et al. (2006) showed that there are significant uncertainties in the vertical distribution in global models, whereas this information is critical in assessing the magnitude and even the sign of the direct radiative forcing. Of particular interest are the distribution of lofted layers (Mattis et al., 2003; Müller et al., 2005; Baars et al., 2012) and the identification of complex scenes involving both aerosols and clouds (Chand et al., 2008).

The South AMerican Biomass Burning Analysis (SAMBBA) campaign was an intensive field project (September-October 2012), aimed at collecting information on the atmosphere of the Amazon basin during the dry season and the transition into the wet season (Angelo, 2012). One important focus has been the impact of biomass burning aerosol on the radiation budget, and its feedback on the dynamics and hydrological cycle, including the influence on numerical weather predictions, climate, and air quality. The partnership involved mainly scientists from Brazil (National Institute for Space Research, INPE, and University of Sao Paulo) and from the United Kingdom (the Met Office and the Natural Environment Research Council).

\section{Research flights}

During SAMBBA, the Facility for Airborne Atmospheric Measurements (FAAM) research aircraft was based in Porto Velho, Brazil $\left(8^{\circ} 44^{\prime} \mathrm{S} 63^{\circ} 54^{\prime} \mathrm{W}\right)$, and 20 research flights were carried out between 14 September and 3 October 2012, totalling $65 \mathrm{~h}$ of atmospheric research flying. Porto Velho lies in the state of Rhondonia, where biomass burning for deforestation and agriculture is prevalent, and a large deforested area is evident. The flights sampled a wide range of conditions, from very low concentrations of gas phase and aerosol species over the pristine Amazonia rainforest, through to major fire plumes emitting very large amounts of pollutants. Some of the flights were coordinated with satellite overpasses, which allowed combining aircraft measurements with spaceborne remote sensing (see, e.g., Marenco et al., 2014).

The aircraft was equipped with several probes, able to sample the atmosphere using both in situ and remote-sensing techniques. Each research flight was planned around one of the following goals: (a) in situ characterisation of fresh plumes (FP), achieved by flying at low level in the immediate vicinity of a fire and sampling the aerosols, trace gases and thermodynamic structure; (b) radiative closure (RC) studies, achieved with a series of stacked aircraft runs and profiles above a limited area, in order to tie together the information derived by remote sensing and the in situ probes; and (c) survey flights (SF) at high altitude, where the properties of the atmosphere are mainly sampled with remote-sensing techniques. Besides Porto Velho (PV), the airports in Rio Branco (450 km WSW of PV), Manaus (760 km NE of PV) and Palmas (1700 km E of PV) were also used.

The circulation in this season is typically dominated by moderate to strong Easterlies (trade winds), which build up large aerosol burdens over Western Amazonia, where the 
low-mid tropospheric circulation is halted by the Andes. In this season, the north-western part of the basin is characterised by the development of deep convective events accompanied by brief but intense precipitation, whereas the Southern and Eastern parts are typically dry. The season in 2012, however, differed somewhat from the climatology. A Northwesterly circulation on the Southwestern part of the basin dispersed the aerosols, and as a result only a moderate aerosol optical depth (AOD) was observed. Moreover, convective precipitation spread further East than usual during the second half of September.

Nevertheless, burning activity continued through the majority of the campaign period, and significant aerosol loading was found during most of the flights. In the majority of cases, a variety of measurements confirmed that the aerosols can be ascribed to smoke originated from forest fires. A general feature throughout the campaign was the persistence of aerosols above the boundary layer, with plumes up to altitudes of 4-6 km, presumably caused by deep convection and lifting. In situ observations with wing-mounted optical particle counters (PCASP and CDP; see, e.g., Liu et al., 1992; Lance et al., 2010; Rosenberg et al., 2012; Ryder et al., 2013) showed a predominance of fine mode particles at all levels (elevated and near-surface). Moreover, measurements with the on-board AL 5002 VUV Fast Fluorescence CO Analyser (Gerbig et al., 1996, 1999; Palmer et al., 2013) showed high carbon monoxide concentrations.

The present study focuses on the results from the airborne lidar during the high-altitude portions of six selected flights, between 16 and 29 September (see Table 1 and Fig. 1). The criterion for selecting the flights has been the availability of sufficiently extended high-altitude and cloud-free sections, so that the aerosol extinction vertical profile could be estimated from the lidar. The six flights span the region between $8.5-12^{\circ} \mathrm{N}$ and $46-68^{\circ} \mathrm{W}$, covering a distance of $\sim 2200 \mathrm{~km}$ extending along an East-West axis across the Brazilian Amazon basin, at an approximate mean latitude of $10^{\circ} \mathrm{S}$.

\section{Measurements}

Observations of atmospheric aerosols have been acquired with the ALS-450 elastic backscattering lidar mounted on the FAAM research aircraft. This is an instrument manufactured by Leosphere; it is operated at a wavelength of $355 \mathrm{~nm}$; and it is mounted in a nadir-looking geometry (Marenco et al., 2011). The system specifications are summarised in Marenco et al. (2014) and a more detailed description of the instrument can be found in Lolli et al. (2011) and Chazette et al. (2012).

Lidar signals were acquired with an integration time of $2 \mathrm{~s}$ and a vertical resolution of $1.5 \mathrm{~m}$. The analogue and photon counting signals are merged at pre-processing by normalisation in an overlap area chosen based on photon-counting thresholds. Cloud signal in the vertical profiles was detected as a "large spike", and the thresholds given in Allen et al.

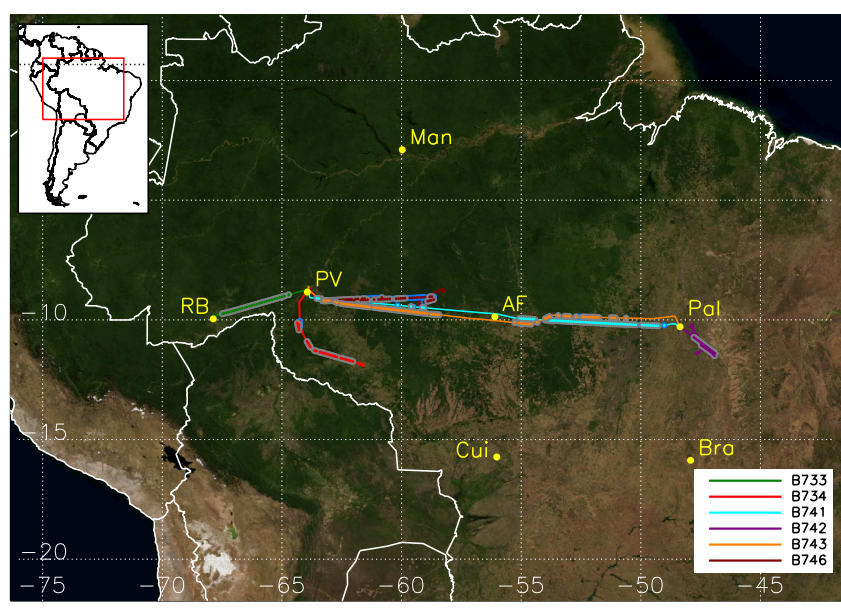

Figure 1. Ground tracks for the six research flights listed in Table 1. The location of the valid lidar profiles used for the computation of aerosol extinction is highlighted as follows: grey, profiles that pass our quality control test; blue, remaining profiles. The following locations are also shown: Porto Velho (PV), Rio Branco (RB), Alta Floresta (AF), Palmas (Pal), Manaus (Man), Cuiabà (Cui), and Brasilia (Bra).

(2014) were applied to determine their top height at 2 s resolution.

In order to determine the aerosol properties, further integration and vertical smoothing have been applied during data processing, to reduce shot noise: the aerosol data presented here therefore have a vertical resolution of $45 \mathrm{~m}$ and an integration time of $1 \mathrm{~min}$. This integration time corresponds to a $9 \pm 2 \mathrm{~km}$ footprint, at typical aircraft speeds.

A first data selection was done as follows: all lidar signals acquired when the aircraft was flying at an altitude lower than $4 \mathrm{~km}$ have been omitted, and data have been discarded if the lidar was pointing at more than $10^{\circ}$ off the vertical (due to the aircraft turning). Lidar signals within $300 \mathrm{~m}$ of the aircraft have been discarded, due to incomplete overlap between the emitter and the receiver field-of-view, and at the far end profiles have been truncated to remove the surface spike and any data beyond it. As a general rule, a vertical profile where a cloud was detected has either been omitted completely, or has been omitted in the portion between the surface and the cloud top. However, in a small number of cases where the cloud optical depth has been considered sufficiently small, so as to not affect the derivation of aerosol properties, data below a cloud have been kept but the cloud layer itself has been rejected.

All assumptions have been reviewed manually, on a profile-by-profile basis, with the possibility to override the cloud exclusion criteria and to set the reference height interval necessary for the derivation of aerosol extinction. After the data selection discussed above, 334 vertical profiles have been retained. Processing of the data followed a double iteration, first to determine the lidar ratio (extinction-to- 
Table 1. Research flights considered in this article. Time is UTC.

\begin{tabular}{lllllll}
\hline Flight & Date & Takeoff & Landing & Latitude & Longitude & Type* $^{*}$ \\
\hline B733 & 16 Sep & Rio Branco, 13:51 & Porto Velho, 14:45 & $8.9-9.8^{\circ} \mathrm{S}$ & $64.5-67.6^{\circ} \mathrm{W}$ & brief SF \\
B734 & 18 Sep & Porto Velho, 12:05 & Porto Velho, 16:01 & $8.9-11.9^{\circ} \mathrm{S}$ & $61.6-64.4^{\circ} \mathrm{W}$ & $\mathrm{RC}$ \\
B741 & 26 Sep & Porto Velho, 12:53 & Palmas, 16:08 & $8.8-10.2^{\circ} \mathrm{S}$ & $48.7-63.9^{\circ} \mathrm{W}$ & $\mathrm{SF}$ \\
B742 & 27 Sep & Palmas, 12:52 & Palmas, 16:17 & $10.2-11.5^{\circ} \mathrm{S}$ & $46.8-48.1^{\circ} \mathrm{W}$ & $\mathrm{FP}$ \\
B743 & 27 Sep & Palmas, 18:08 & Porto Velho, 21:34 & $9.0-10.2^{\circ} \mathrm{S}$ & $48.4-63.6^{\circ} \mathrm{W}$ & $\mathrm{SF}$ \\
B746 & 29 Sep & Porto Velho, 12:54 & Porto Velho, 16:38 & $8.7-9.4^{\circ} \mathrm{S}$ & $58.2-63.7^{\circ} \mathrm{W}$ & $\mathrm{FP}+\mathrm{SF}$ \\
\hline
\end{tabular}

* Flight type: FP: fresh plume sampling, mainly in situ; RC: radiative closure, combining in situ and remote sensing; SF: high-altitude survey flight.

backscatter ratio), and subsequently to process the data set to determine the extinction coefficient. The method detailed in Marenco (2013) is at the basis of this processing, and it is based on setting the reference within the aerosol layer, rather than on a Rayleigh-scattering portion of the atmosphere. The slope method is used for a first estimate of the extinction coefficient at the reference, based on the lidar measurements themselves. As illustrated in that paper, in this geometry and at this wavelength the forward solution to the lidar equation is unstable and cannot be used when the aerosol layers are deep and their extinction is large; hence the need for using this method. Marenco et al. (2014) illustrates the application of this method in comparison with CALIPSO retrievals and to constrained retrievals using AERONET.

\subsection{Lidar ratio}

An initial subset of the lidar profiles has been selected, where the signature of Rayleigh scattering has been clearly identified above the aerosol layers. This circumstance permits iteration using the method described in Marenco (2013) by varying the lidar ratio (assumed constant with height), until a good match to the overlying Rayleigh scattering layer is reached: in this way, the lidar ratio itself can be estimated. Out of these lidar profiles, 270 indicate at least a moderate aerosol load (AOD > 0.25), and they have been kept to compute a distribution: results are displayed in Fig. 2b. The data set follows a Gaussian distribution, and is characterised by a mean and standard deviation of 73.1 and $6.3 \mathrm{sr}$, respectively. Moreover, Fig. 2a shows that the distribution is not significantly affected by how we choose the acceptance threshold $(A O D>0.25)$. The lidar ratio determined in this way is not substantially affected by the choice of the lower reference extinction, and is instead mainly affected by the higher layers, where the transition between a large extinction coefficient and a molecular layer is encountered. This estimate of the lidar ratio for biomass burning aerosols is in agreement with the findings reported in Omar et al. (2009), Baars et al. (2012), Groß et al. (2012), and Lopes et al. (2013).

The lidar ratio so determined, $73 \pm 6 \mathrm{sr}$, has been compared to Mie scattering computations. Figure 3a displays the campaign mean particle size-distribution (PSD) determined with
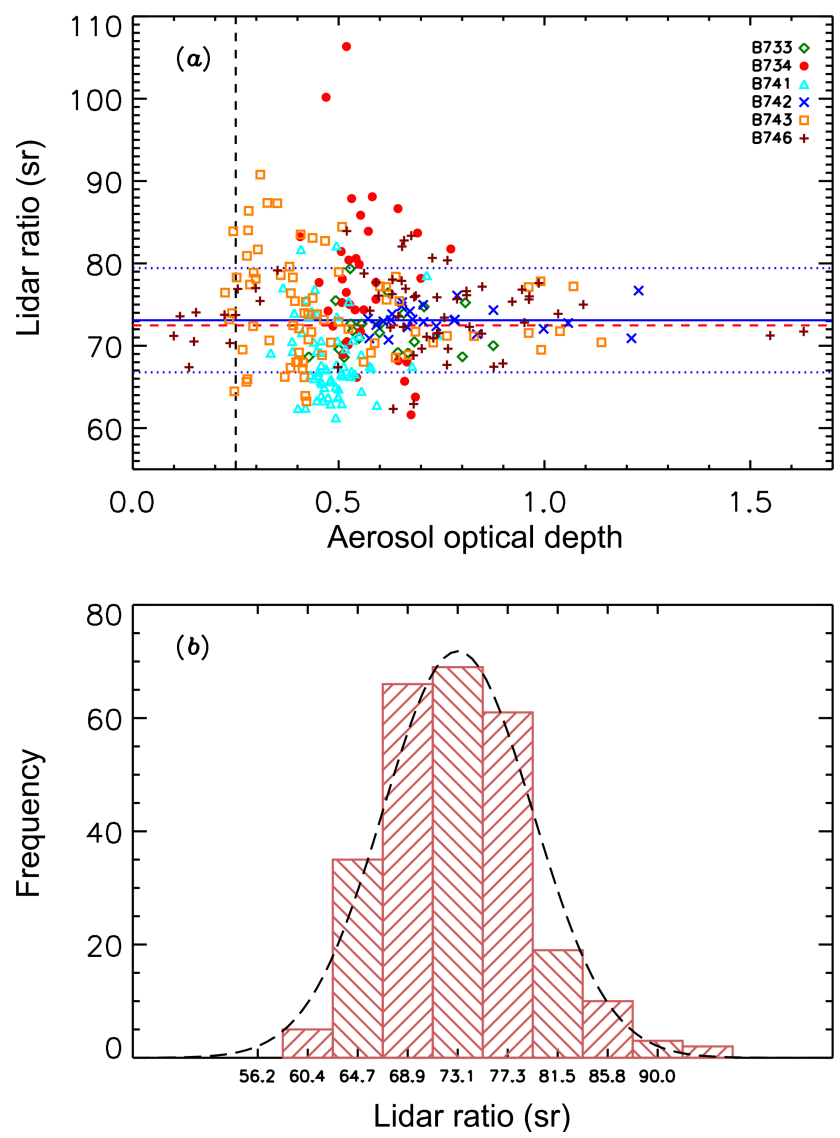

Figure 2. (a) Lidar ratio and AOD, determined for each lidar profile (see text). The data points are colour-coded with the flight number. The horizontal blue solid line indicates the mean, the blue dotted lines indicate one standard deviation from the mean, and the dashed red line indicates the median. The vertical dashed line indicates the threshold (AOD > 0.25) that has been applied to the data set. (b) Histogram of lidar ratio determinations, for 270 profiles with AOD > 0.25. Mean: $73.1 \mathrm{sr}$, standard deviation: $6.3 \mathrm{sr}$, median: 72.5 sr. A gaussian curve with the same mean and standard deviation is overplotted (dashed line). 
(a)
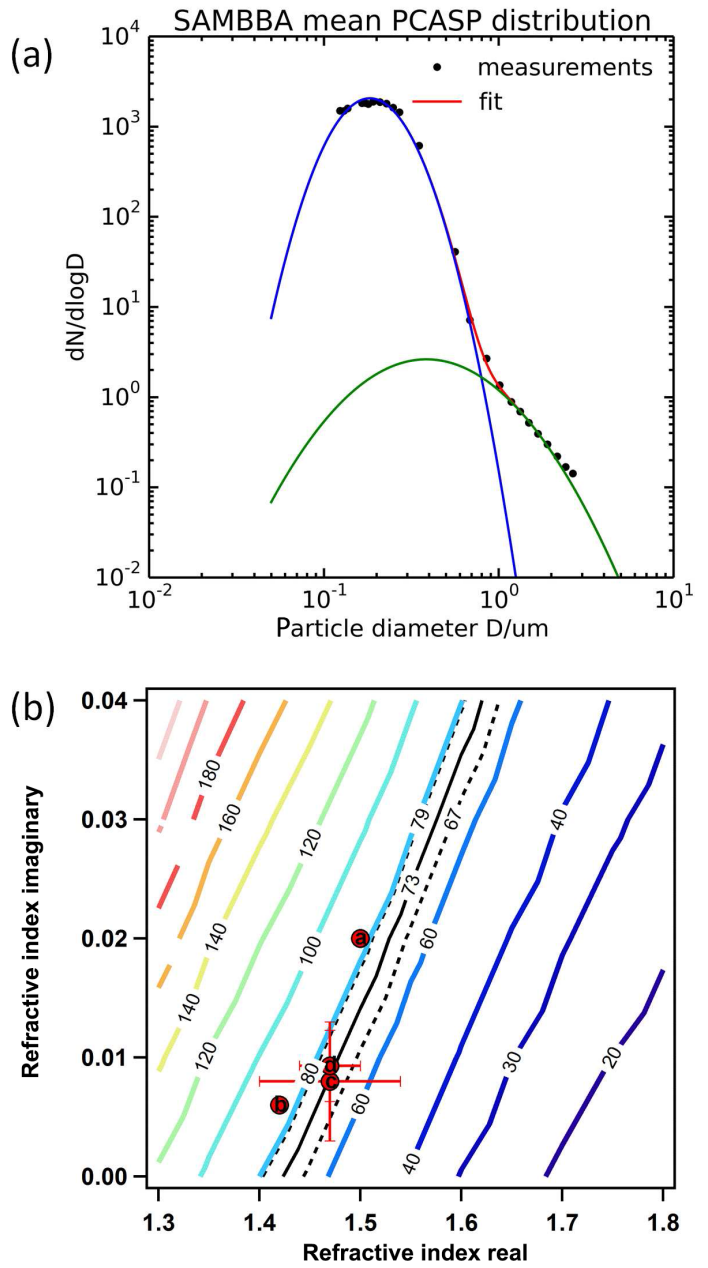

Figure 3. (a) SAMBBA campaign mean particle size-distribution, determined with the wing-mounted PCASP optical particle counter (black dots). The fit with a bimodal lognormal is also shown; the parameters of the two lognormals are as follows: accumulation mode: $D_{p}=0.184 \mu \mathrm{m}, \sigma=1.47$, and $N_{t}=868.5$. Coarse mode: $D_{p}=0.387 \mu \mathrm{m}, \sigma=2.13$, and $N_{t}=2.16$. (b) Contours of the lidar ratio computed for the campaign mean particle size-distribution, by varying the refractive index. The black solid and dotted lines indicate the mean and standard deviation of the lidar ratio determined by lidar $(73 \pm 6 \mathrm{sr})$. The red dots show estimates of the Amazonian biomass burning aerosol refractive index taken from the literature: (a) $1.5-0.02 i$ (Reid and Hobbs, 1998); (b) $1.42-0.006 i$ (Guyon et al., 2003); (c) $(1.47 \pm 0.07)-(0.008 \pm 0.005) i$ (Rizzo et al., 2013); (d) $(1.47 \pm 0.03)-(0.0093 \pm 0.003) i$ (Dubovik et al., 2002).

the PCASP, and its fit using two lognormals, each of which is in the form

$n(D)=\frac{N_{t}}{\sqrt{2 \pi} \ln \sigma} \frac{e^{-\frac{1}{2}\left(\frac{\ln D / D_{p}}{\ln \sigma}\right)^{2}}}{D}$,

where $D$ is diameter, and $D_{p}, \sigma$, and $N_{t}$ are three fitted parameters (Johnson et al., 2016). We have computed the lidar ratio for this size-distribution and for a range of refractive indices; see Fig. 3b. The resulting lidar ratio is highly dependent on the real and imaginary parts; refractive index estimates from the literature are also shown in the figure. The lidar derivation of $73 \pm 6 \mathrm{sr}$ is compatible, for instance, with refractive indices from Rizzo et al. (2013) and Dubovik et al. (2002). Note that the estimates computed with refractive indices from Reid and Hobbs (1998) and Guyon et al. (2003) also do not fall too far off.

\subsection{Estimate of the aerosol extinction coefficient}

Following the result of the first iteration on the lidar data, a lidar ratio of $73 \mathrm{sr}$ has been adopted for the full data set, and a second iteration with the method introduced in Marenco (2013) has been applied to determine the aerosol extinction coefficient for all the 334 profiles. This method (slopeFernald method) is a variant of the Fernald-Klett method (Fernald, 1984; Klett, 1985), where the reference is taken within an aerosol layer: this permits using the stable (inward) solution to the lidar equation in the unfavourable geometry represented by a nadir-looking lidar. Note that this choice is necessary if, as found during this campaign, no aerosolfree region below the aerosol layers is available. Figure 4 shows typical resulting estimates of the aerosol extinction coefficient, for a subset of the vertical profiles (this selection is purely illustrative in purpose). For each profile, an estimate of the uncertainty that results from the retrieval assumptions has been computed, by repeating the derivation after having varied the lidar ratio by \pm 6 sr (this being the uncertainty adopted above), and after having varied the extinction value at the reference by $\pm 50 \%$ ( $1 \sigma$ statistical errors). The latter value reflects the large uncertainty that arises from the Marenco (2013) method, since reference is taken within an aerosol layer instead of in Rayleigh scattering conditions. Note however, how quickly the uncertainty decreases when moving upwards from the reference height; the opposite is unfortunately also true, i.e. where the reference height is taken at an altitude, then uncertainty increases up to $\pm 100 \%$ near the surface. In summary, very large uncertainties exist in the bottom part of the vertical profiles, but they are quickly damped when moving towards the higher layers. At the top of the profiles, uncertainty is instead driven by the lidar ratio, and is generally small.

\section{Observed aerosol distribution}

Figures 5 and 6 display the cross-sections of aerosol extinction coefficient and of its estimated uncertainty, as a function of along-track distance and height. Generally, all six flights show a similar structure, with a moderate magnitude of aerosol extinction, of the order of $150-200 \mathrm{Mm}^{-1}$, between the surface and an upper altitude of 4-6 km, with some localised patches showing higher magnitudes. This general vertical structure was broadly coherent over distances of 

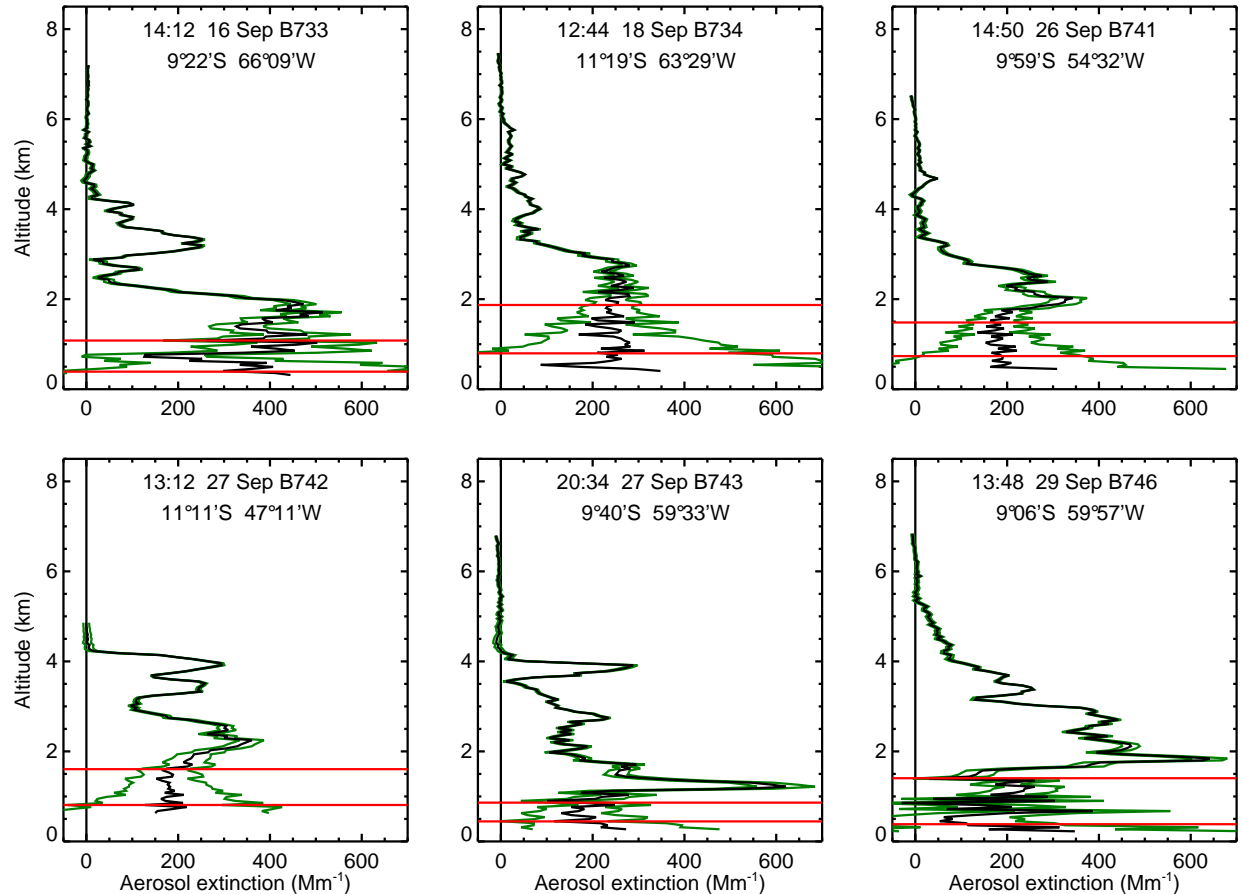

Figure 4. A sample of the lidar vertical profiles of aerosol extinction coefficient, discussed in this paper. The green lines indicate the estimate of uncertainty. The red lines indicate the reference height interval used (different for each profile). The time, date, flight number and coordinates are indicated in the title to each plot. Each profile corresponds to an integration time of $1 \mathrm{~min}$.

thousands of kilometres and persisted over the 2-week period studied here.

At smaller spatial scales, some noticeable features were observed, and are described as follows. Flight B742 shows four features where a large extinction coefficient (approaching $1000 \mathrm{Mm}^{-1}$ ) is detected at an altitude of $1.25 \mathrm{~km}$, at along-track distances of $115,135,310$ and $360 \mathrm{~km}$. These correspond to plumes from single fires that were seen from the cockpit. Since the aircraft was flying back and forth over the same area, these smoke plumes were all located within a maximum distance of $\sim 25 \mathrm{~km}$ from each other, and in fact the ones observed at 310 and $360 \mathrm{~km}$ along-track distance were at the same location.

Flight B743 also shows a plume from a single fire, centred at an along-track distance of $1260 \mathrm{~km}$; it extends from the surface to $2 \mathrm{~km}$ altitude and has a size of $\sim 50 \mathrm{~km}$ in the along-track horizontal direction; in this plume a peak extinction of $1270 \pm 40 \mathrm{Mm}^{-1}$ was encountered. Moreover, a higher altitude feature is observed, well above the aerosol layer, and co-located with this intense plume but apparently disconnected from it: its altitude is $3.7-4 \mathrm{~km}$, with a depth varying between 200 and $400 \mathrm{~m}$ (FWHM). Its horizontal extent is of $270 \mathrm{~km}$ along-track, its aerosol optical depth (AOD) peaks 0.09 , and its extinction coefficient peaks $300 \mathrm{Mm}^{-1}$. The origin of this higher altitude feature is uncertain: it could have been released by the same fire at an earlier time, i.e. if the fire radiative power had been at anytime stronger; it may also have originated from some other nearby fire; and finally it may have been transported over a longer distance.

Moreover, in flights B741 (first part) and B746 the presence of clouds with tops at $2-4 \mathrm{~km}$ obscures the bottom part of the aerosol layer; above these clouds, large extinction coefficients are detected, peaking $1000-1500 \mathrm{Mm}^{-1}$. These large values are likely to be either directly caused by nearby fires (hidden by the clouds themselves), or as a result of convective lifting and detraining of smoke into a layer around the cloud-top.

From the aerosol extinction coefficient described above, a few quantities have been computed. The layer extinction is computed as the vertically averaged extinction, and the aerosol optical depth (AOD) as the vertically integrated extinction. The layer height has been defined, for each vertical profile, as the weighted average of the aerosol vertical distribution, and the layer depth as $\sqrt{2} \times(\mathrm{AOD}) /($ peak extinction). Note that the definition of layer depth can be quite arbitrary; however, the above definitions are consistent with Marenco et al. (2011). The layer height, layer depth, layer extinction and aerosol optical depth have been computed for each vertical profile in the data set. Note, however, that these derived quantities can be affected by the vertical extent of the available data, which in turn is affected by aircraft altitude, terrain height, and the presence of low clouds. As a quality control test, profiles for which the relative error on AOD was larger than $50 \%$, and profiles that were truncated (due 

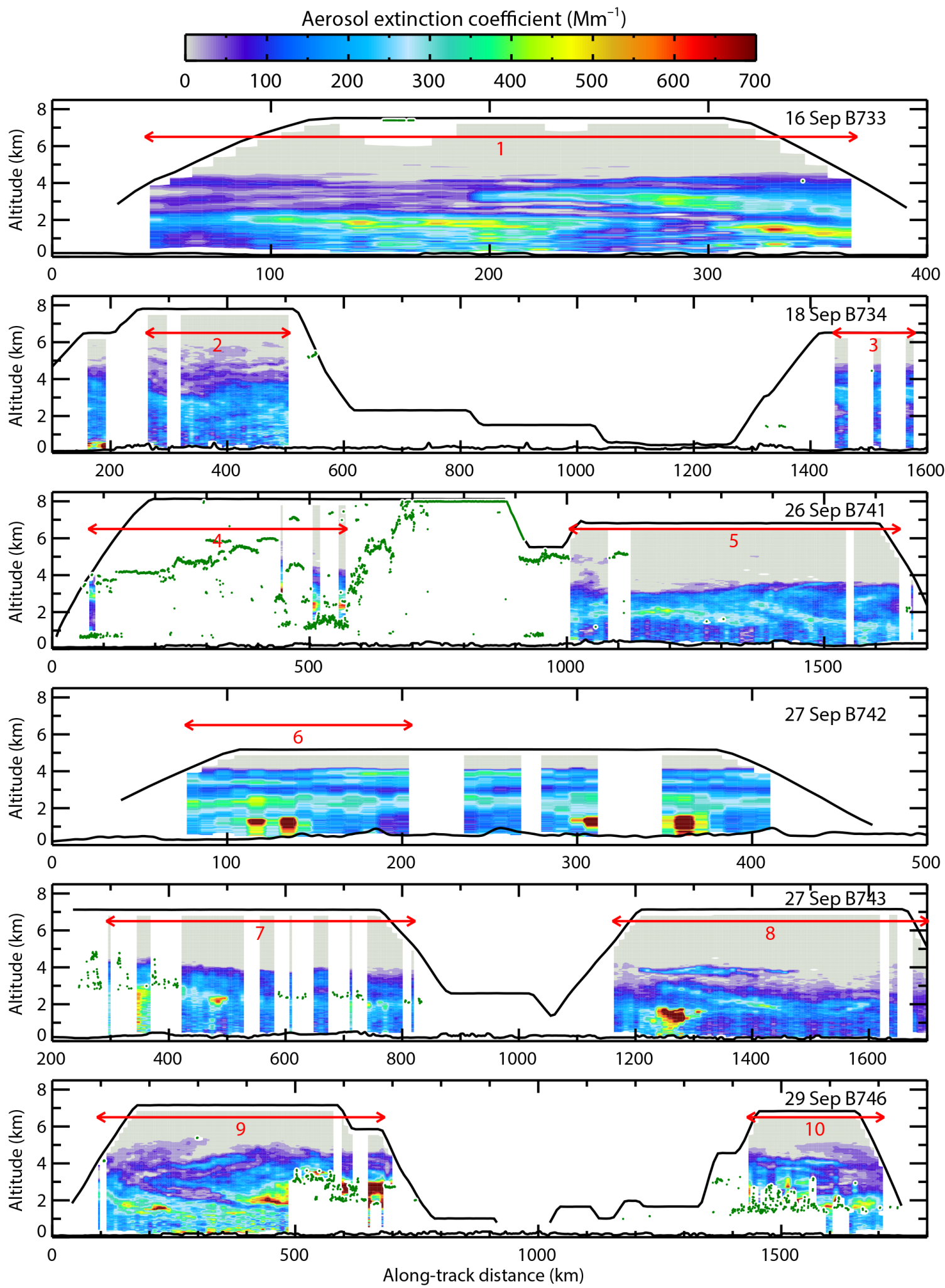

Figure 5. Cross-sections of the aerosol extinction coefficient determined from the lidar for the six research flights with a 1-min integration time. The black lines indicate the aircraft altitude and the surface elevation from a digital elevation model, respectively. The green dots indicate cloud tops detected with the lidar at $2 \mathrm{~s}$ resolution. The red numbered arrows indicate the selected sections for the characterisation of the aerosol layer (see Table 2). 

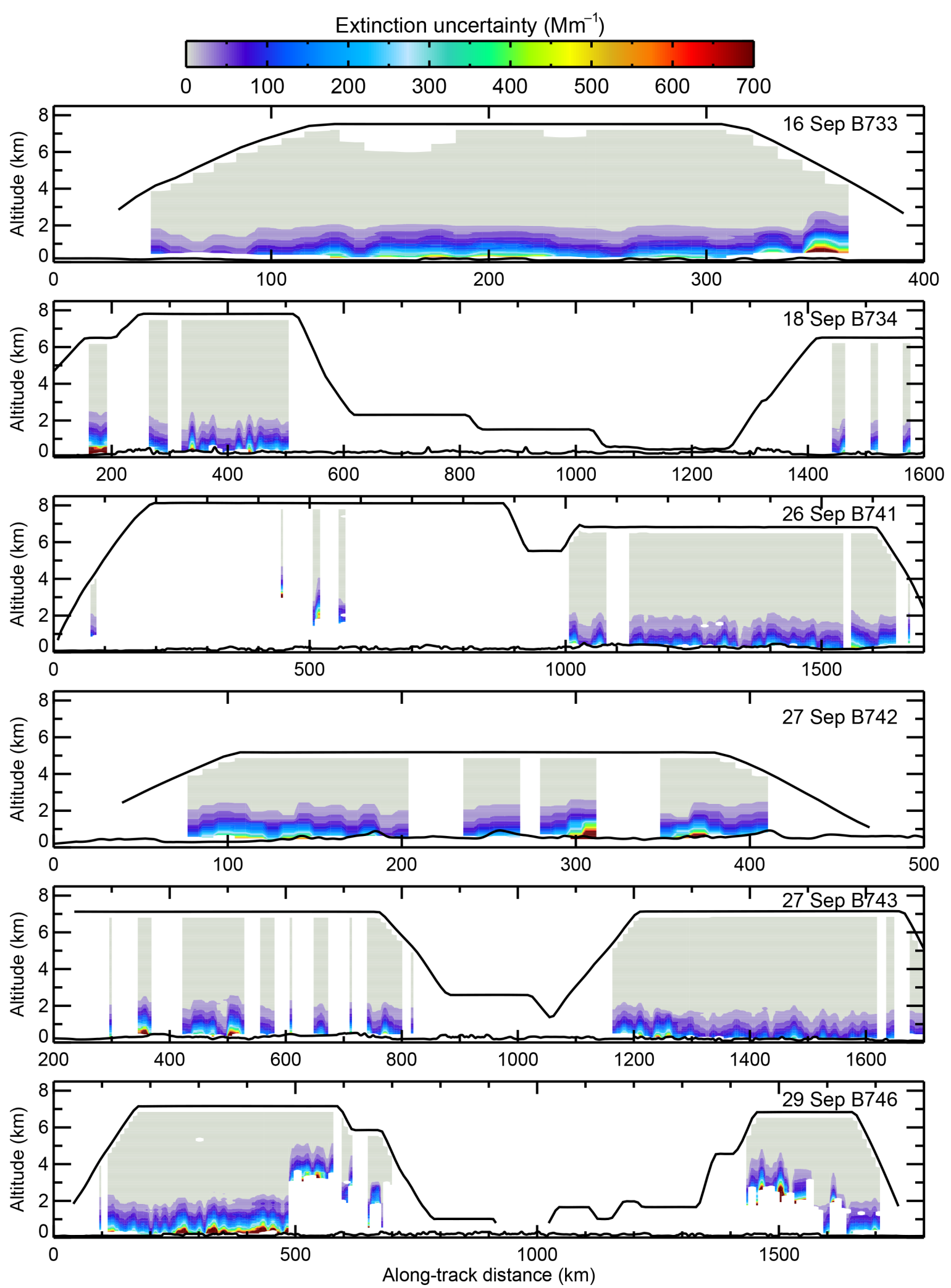

Figure 6. Cross-sections of the aerosol extinction coefficient uncertainty. 
Table 2. Flight sections considered for the characterisation of the aerosol layer, displayed with red arrows in Fig. 5. For each section, the layer height, layer depth, layer extinction and aerosol optical depth are listed (see text). For each quantity, the average and standard deviation are shown; for the layer extinction and aerosol optical depth, maximum values are shown as well (in parentheses). The results for the whole data set are listed as well.

\begin{tabular}{llrrrrrr}
\hline $\begin{array}{l}\text { Section } \\
\text { number }\end{array}$ & $\begin{array}{l}\text { Flight } \\
\text { number }\end{array}$ & Time & $\begin{array}{r}\text { Number of } \\
\text { profiles }\end{array}$ & $\begin{array}{r}\text { Layer height } \\
(\mathrm{km})\end{array}$ & $\begin{array}{r}\text { Layer depth } \\
(\mathrm{km})\end{array}$ & $\begin{array}{r}\text { Layer extinction } \\
\left(\mathrm{Mm}^{-1}\right)\end{array}$ & $\begin{array}{r}\text { Aerosol optical depth } \\
(-)\end{array}$ \\
\hline 1 & B733 & $13: 56-14: 27$ & 28 & $2.04 \pm 0.28$ & $2.27 \pm 0.23$ & $113 \pm 31(224)$ & $0.68 \pm 0.18(1.02)$ \\
2 & B734 & $12: 35-13: 04$ & 23 & $2.39 \pm 0.13$ & $3.05 \pm 0.47$ & $93 \pm 12(117)$ & $0.66 \pm 0.09(0.84)$ \\
3 & B734 & $15: 10-15: 26$ & 7 & $2.53 \pm 0.08$ & $2.86 \pm 0.37$ & $102 \pm 9(117)$ & $0.61 \pm 0.06(0.70)$ \\
4 & B741 & $13: 02-13: 56$ & 5 & $2.63 \pm 0.07$ & $1.47 \pm 0.35$ & $132 \pm 22(173)$ & $0.63 \pm 0.17(0.78)$ \\
5 & B741 & $14: 43-15: 53$ & 61 & $1.85 \pm 0.12$ & $2.37 \pm 0.38$ & $91 \pm 11(117)$ & $0.55 \pm 0.07(0.71)$ \\
6 & B742 & $13: 02-13: 17$ & 14 & $2.26 \pm 0.26$ & $2.82 \pm 0.50$ & $212 \pm 48(311)$ & $0.89 \pm 0.22(1.36)$ \\
7 & B743 & $18: 39-19: 35$ & 29 & $2.05 \pm 0.16$ & $2.72 \pm 0.53$ & $109 \pm 37(227)$ & $0.68 \pm 0.25(1.43)$ \\
8 & B743 & $20: 20-21: 18$ & 50 & $1.69 \pm 0.20$ & $2.09 \pm 0.41$ & $75 \pm 35(195)$ & $0.48 \pm 0.24(1.29)$ \\
9 & B746 & $13: 06-14: 11$ & 39 & $2.07 \pm 0.29$ & $2.17 \pm 0.51$ & $161 \pm 58(366)$ & $0.92 \pm 0.25(1.83)$ \\
10 & B746 & $15: 52-16: 23$ & 20 & $2.43 \pm 0.60$ & $1.68 \pm 0.50$ & $125 \pm 43(228)$ & $0.61 \pm 0.21(0.90)$ \\
\hline All data & & & 276 & $2.03 \pm 0.36$ & $2.34 \pm 0.57$ & $112 \pm 49(366)$ & $0.65 \pm 0.24(1.83)$ \\
\hline
\end{tabular}

to cloud) at a lower boundary which was $2.5 \mathrm{~km}$ or higher above mean sea level have not been included in the discussion of the derived quantities described above.

In order to characterise the aerosol layer in terms of representative properties, the data set has been divided in the sections listed in Table 2, numbered 1-10, and also displayed with red arrows in Fig. 5. For each of the shorter flights, a single section has been considered, whereas when the distance travelled exceeded $1000 \mathrm{~km}$ two flight sections have been considered. For flight B742, since the aircraft travelled back and forth over the same ground track several times, only the first part of the lidar cross-section has been considered. Due to the above quality criteria and to the fact that some flight portions have not been included (e.g. the second part of flight B742), the number of retained profiles is reduced from 334 to 276. Table 2 summarizes the flight sections averages and standard deviations for the considered quantities; note that in this context, standard deviation is a measure of variability for each given quantity. The maximum of the layer extinction and of the aerosol optical depth is also listed for each section; the maximum of the layer extinction is in general different and lower than the maximum value of extinction that is encountered in each section (layer extinction being a vertically averaged quantity).

The geometrical properties of the aerosol vertical distribution, i.e. the layer height and layer depth, show a limited variability within each section, with standard deviation around $10-15 \%$ for layer height and $15-25 \%$ for layer depth. Flight B746 represents an exception and shows larger variability in its second part (Sect. 10); however, for this flight a large proportion of profiles are truncated due to low cloud, and therefore the remaining data may possibly not provide a representative sample. Averaged over all six flights, the layer height is $2.0 \pm 0.4 \mathrm{~km}$, and the layer depth is $2.3 \pm 0.6$ (average and standard deviation). This indicates that the vertical distribution of the aerosols does not vary much, despite the large distance travelled by the aircraft (more than $2200 \mathrm{~km}$ between the eastmost and westmost lidar profiles) and the relatively long time between the first and the last flight (14 days).

The quantitative properties, i.e. mean extinction and AOD, display a larger variability, as expected; however, this variability is not huge. The per-section average of layer extinction varies between 75 and $200 \mathrm{Mm}^{-1}$ and the per-section average of AOD is between 0.5 and 0.9 , each of these quantities showing a standard deviation of 10-50\% in each flight section. When computed over all six flights, the average and standard deviation of these quantities is $112 \pm 49 \mathrm{Mm}^{-1}$ and $0.65 \pm 0.24$, respectively, and the maximum values encountered over the data set were about three times larger than the average. The distribution of the layer properties, derived by airborne lidar for the six flights considered in this paper, is shown in Fig. 7.

The mean vertical distributions of aerosol extinction for each of the ten sections are shown in Fig. 8. The average over the ten sections is displayed in Fig. 9, and shows a general structure that can be summarised as follows. Near the surface, and up to an altitude of $\sim 1 \mathrm{~km}$, a surface layer of extinction coefficient $\sim 200 \mathrm{Mm}^{-1}$ is observed. Above this layer, an elevated layer is found which has a slightly larger extinction coefficient (peaking $\sim 250 \mathrm{Mm}^{-1}$ ) and a significant depth, extending from $\sim 1$ to $\sim 5 \mathrm{~km}$ altitude. When looking at the individual sections (Fig. 8), variations around this general structure can be observed: the lower layer in some of the flights extends a bit higher (up to $\sim 1.5 \mathrm{~km}$ ) and can show a magnitude of the aerosol extinction coefficient of $150-300 \mathrm{Mm}^{-1}$; and the aerosols above can extend, depending on the flight section, up to an altitude between 4 and $6 \mathrm{~km}$. The elevated aerosols show as a single well-defined elevated layer in Sects. 2, 5 and 7 and as a more structured, 

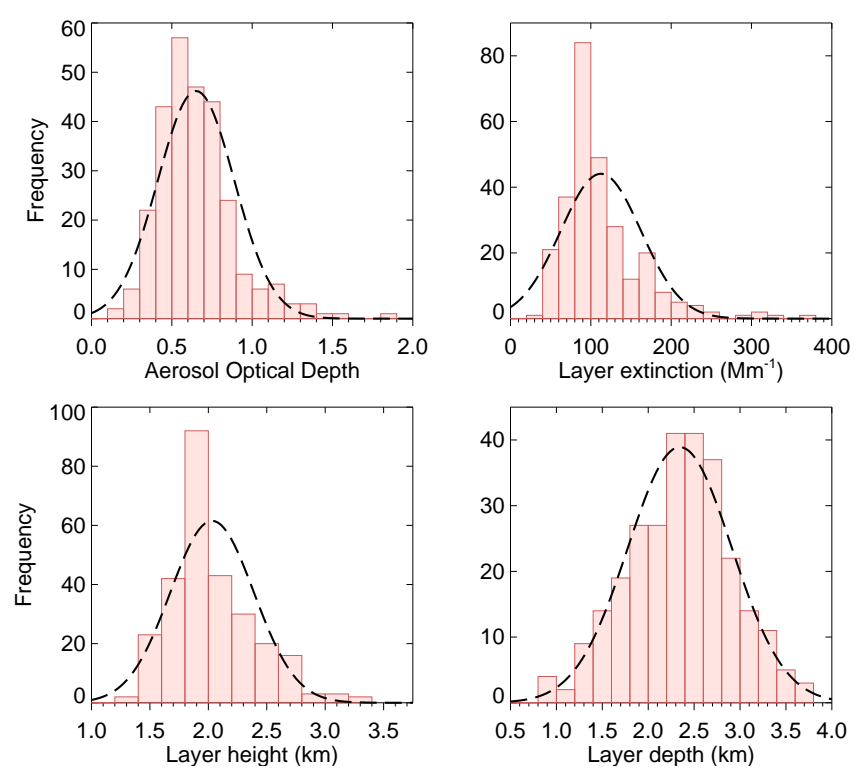

Figure 7. Distributions of aircraft lidar observations of AOD, layer extinction, layer height and layer depth, for the whole data set considered in this paper (276 vertical profiles). A Gaussian curve with the mean and standard deviation of the data set is superimposed (dashed line).

multi-layer atmosphere in the other sections. The signature of the individual fire plumes described above can be found in these average profiles; see e.g. the maximum at an altitude of $\sim 1.25 \mathrm{~km}$ in Sect. 6, and at an altitude of $\sim 1.6 \mathrm{~km}$ in Sect. 8. These layers also show a larger standard deviation, reflecting the variability between in-plume and out-of-plume conditions. Note also that Sects. 4, 9 and 10 are affected by low clouds with large smoke concentrations above; this is reflected in the large values of the mean +1 standard deviation (up to $600-800 \mathrm{Mm}^{-1}$ ).

\section{Model simulations}

The lidar data have been used to evaluate aerosol simulations from two prediction models: (i) a limited area model (LAM) configuration of the Met Office Unified Model (MetUM), and (ii) aerosol forecasts issued by the European Centre for Medium-range Weather Forecasts (ECMWF-MACC). The MetUM limited area model was set up for the SAMBBA campaign over the Amazonia domain (latitude $25^{\circ} \mathrm{S}-18^{\circ} \mathrm{N}$, longitude $85-32^{\circ} \mathrm{W}$ ), and has a resolution of $12 \mathrm{~km}$, with 70 levels in the vertical (Kolusu et al., 2015). Lateral boundary conditions for the meteorological fields were driven provided by the operational global configuration of the MetUM (Global Atmosphere 3.1, Walters et al., 2011). The ECMWFMACC simulations were global, although analysed here over the Amazonian region only. Both models were initialised using near-real time emissions from the Global Fire Assimilation System (GFAS) emission data set (Kaiser et al., 2012), valid for the forecast base time. The GFAS data are a daily product based on all the Moderate-Resolution Imaging Spectroradiometer (MODIS) overpasses, over the course of any given day. Assimilation using this inventory is known to lead to an underestimation of AOD, due to the lack of detection of small smouldering fires, and fires below canopies and clouds. Studies show that for a better agreement it is therefore necessary to scale up the emissions (Kaiser et al., 2012). Whilst the ECMWF-MACC model used a scale factor of 3.4 (Kaiser et al., 2012), this was reduced to a factor of 1.7 for the MetUM based on an initial assessment of AODs with AERONET and MODIS data earlier in the season.

In the MetUM simulations, biomass burning aerosol was simulated on-line using the CLASSIC aerosol scheme (Bellouin et al., 2011), while all other aerosol species were represented by climatological averages. Direct aerosol effects were included in the simulations, but indirect effects were not. There are a number of uncertainties on some of the assumptions used in the simulations; in particular associated with the potential transport of aerosols from outside the domain boundaries, the rainout of biomass burning aerosols and their ageing, and the source emissions. Aerosol injection was prescribed between 0.1 and $3 \mathrm{~km}$ in height; this is likely to affect the representation of the vertical extent of the aerosol plumes, in particular from larger fires. Moreover, emissions were not updated during the model simulation, and therefore an assumption is made on persistence of the emission field. The CLASSIC aerosol scheme uses a prescribed aerosol size distribution and refractive index, based on Haywood et al. (2003). A climatological hygroscopic growth curve based on Magi and Hobbs (2003) is included in the model, and this information enables the calculation of aerosol optical properties, including extinction coefficient.

The ECMWF-MACC model issued by ECMWF is provided as part of the EU-funded projects Monitoring Atmospheric Composition and Climate, MACC, MACC-II and MACC-III (Morcrette et al., 2009; Benedetti et al., 2009). The initial package of ECMWF physical parameterisations dedicated to aerosol processes mainly follows the treatment of the Laboratoire de Météorologie Dynamique general circulation model, LMD-Z (Boucher et al., 2002; Reddy et al., 2005). Five types of tropospheric aerosols are considered in the model, and are fully coupled with the meteorology: sea salt, dust, organic carbon, black carbon, and sulphate. Prognostic aerosols of natural origin, mineral dust and seasalt, are described using three size bins, and their emissions depend on model parameters (surface winds among others). Anthropogenic emissions are specified using current emission inventories, and biomass burning emissions are taken from the GFAS inventory. The simulations presented here were carried out using an experimental version of the ECMWF-MACC model, which emits biomass burning aerosols at an injection height provided by a Plume Rise Model (PRM) that has been embedded into GFAS (Paugam et al., 2015). The PRM derives injection heights from 
(a) 16 Sep B733 13:56-14:27

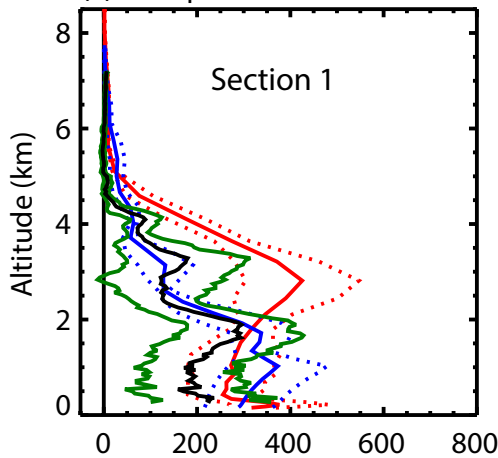

(d) 26 Sep B741 13:02-13:56

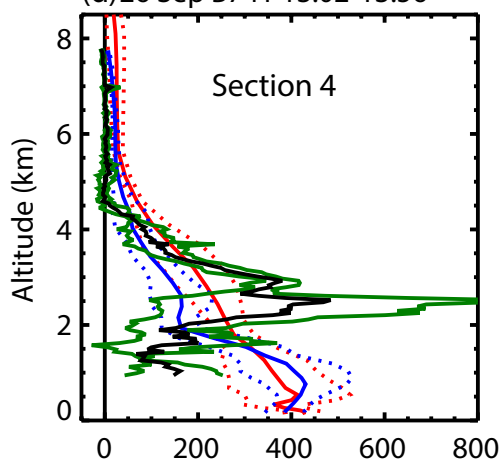

(g)27 Sep B743 18:39-19:35

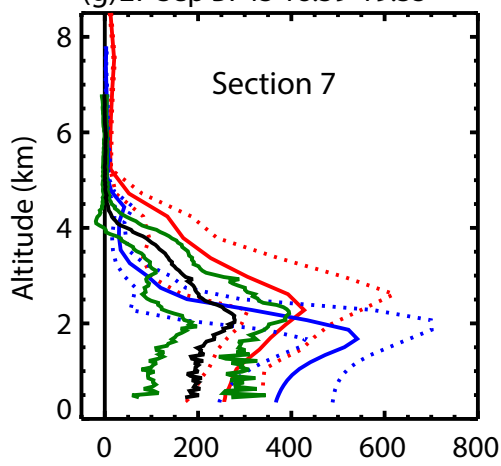

(j) 29 Sep B746 15:52-16:23

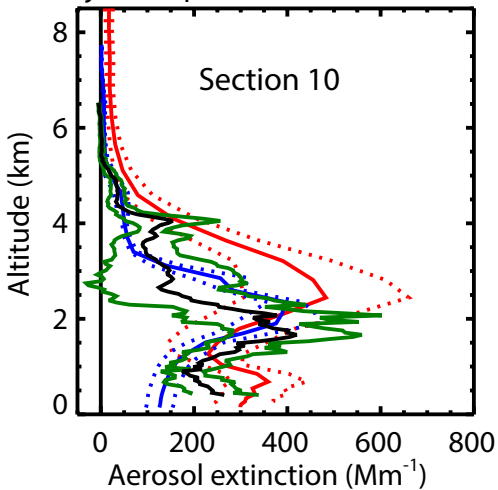

(b) 18 Sep B734 12:35-13:04

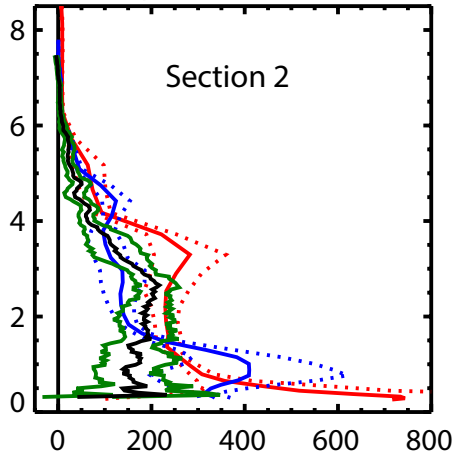

(e) 26 Sep B741 14:43-15:53

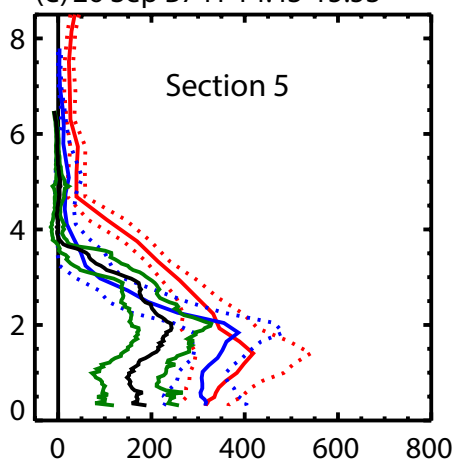

(h)27 Sep B743 20:20-21:18

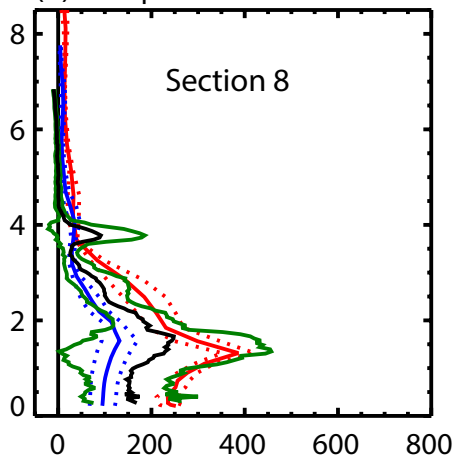

(k) ALL SECTIONS

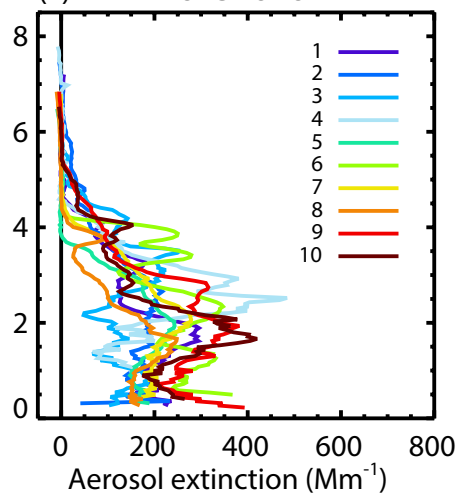

(c) 18 Sep B734 15:10-15:26

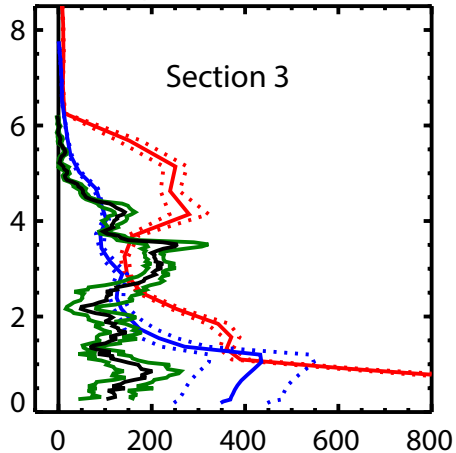

(f) 27 Sep B742 13:02-13:17

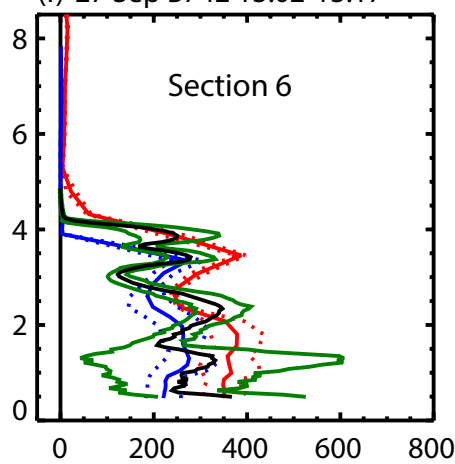

(i) 29 Sep B746 13:06-14:11

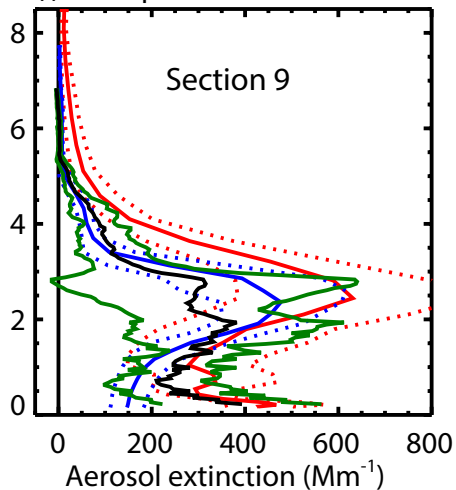

Figure 8. Panels (a-j): summary vertical profiles for each of the 10 flight sections listed in Table 2. Each plot displays the mean vertical profile (black) and the \pm 1 standard deviation curves (green) for the lidar data. The MetUM (blue) and ECMWF-MACC (red) mean vertical profiles and their standard deviation, for each of the sections, are also displayed. Panel (k): the 10 mean lidar vertical profiles shown in panels $(\mathbf{a}-\mathbf{j})$, each representative of a section. 


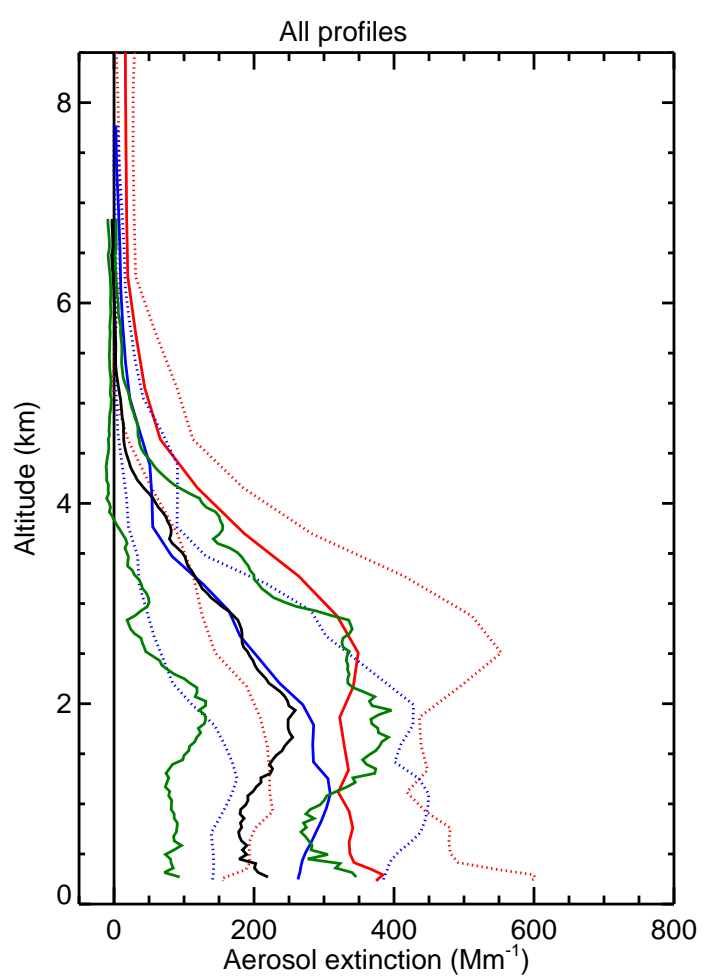

Figure 9. Lidar summary vertical profile resulting from all the 276 lidar profiles (black), together with the curves representing \pm 1 standard deviation (green). The MetUM (blue) and ECMWFMACC (red) mean vertical profiles and their standard deviation are also shown for the same collection of flight sections.

MODIS observations of Fire Radiative Power (FRP) and atmospheric profiles from ECMWF; these are then gridded and assimilated in GFAS, and provided on a daily basis, together with emissions. Moreover, MODIS AOD data are routinely assimilated into the model, in a 4D-Var framework. All data are available online at http://www.copernicus-atmosphere. $\mathrm{eu} /$. The resolution of the ECMWF model is $\sim 80 \mathrm{~km}$ (T255), coarser than that of the MetUM limited area model, and there are 60 model levels.

Figures 10 and 11 show the modelled aerosol extinction coefficient along the tracks of the six flights. Model clouds are also shown for the MetUM (green dashed contours); they are defined as the gridboxes where the cloud fraction is larger than 0.1 or the relative humidity is larger than $90 \%$.

The MetUM represents many realistic features of the aerosol layers, although plumes from individual fires are in some cases not captured. The ECMWF-MACC aerosol field is also realistic, but more smoothed out, as is expected due to its lower resolution.

The comparison between the airborne measurements and the MetUM is quite good for flight B733, where the model predicts elevated aerosol plumes, in good agreement with the observations. Differences appear, for instance, where the model predicts a slightly deeper aerosol layer and at the same time it underestimates the extinction coefficient for the elevated layers. Similar intensities are found at 1.5$2 \mathrm{~km}$, although the features are not in exactly the same position as observed. The ECMWF-MACC model simulates the aerosols as being mainly concentrated in an elevated layer at $\sim 2.5 \mathrm{~km}$, and as having a marked gradient, increasing with along-track distance (eastward). Overall, ECMWF-MACC overestimates the aerosol extinction in this case.

For the first part of flight B734 the lidar observes a relatively homogeneous layer from the surface up to $3-4 \mathrm{~km}$, but with variations in its top altitude and some elevated thin plumes above. A similar distribution is highlighted in the MetUM and ECMWF-MACC models, although once again the exact position of the features is different. In the second part of this flight, however, the lidar highlights a deep elevated plume at $2.5-4.5 \mathrm{~km}$, with an extinction coefficient of the order of $200-250 \mathrm{Mm}^{-1}$. As a comparison, we notice that the MetUM predicts some aerosol in the same place, although optically and geometrically thinner and with an irregular structure within a cloudy field. The ECMWF-MACC, on the other hand, predicts a plume with a similar extinction but a higher altitude (4-6 km).

For flight B741, the difference between the models and the observations is remarkably more pronounced. In fact, for this case both models overestimate aerosols near the surface, and show a rapidly decreasing concentration above $3-4 \mathrm{~km}$ with a highly variable top of the aerosol layer reaching in some places up to $\sim 7 \mathrm{~km}$. In the first part of this flight very little observational data were available, due to the presence of deep clouds; a few lidar profiles are however available, and they indicate an intense aerosol layer $\left(400-700 \mathrm{Mm}^{-1}\right)$ at $2-$ $4 \mathrm{~km}$, hence with much larger altitude than the main layer in both model outputs. In the second part of this flight, the top of the aerosol layer at $3-4 \mathrm{~km}$ is much sharper than in the model predictions, with most of the aerosols being found between $\sim 1$ and $\sim 3 \mathrm{~km}$.

For flight B742, the MetUM shows a slightly smaller aerosol extinction coefficient than the lidar observations, and a slightly shallower aerosol layer, but overall the vertical distribution is well represented, with the exception of the individual fire plumes, that appear much fainter. For the same flight ECMWF-MACC shows larger extinction values.

For B743, the MetUM displays a large gradient of the extinction coefficient along the track, with very large values on the first part of the graph (eastern end) and small values towards the right-hand side (Western end of the flight). The predicted haze layer, moreover, is shallower than the observations. The ECMWF-MACC model displays a larger extinction than the MetUM and a slightly deeper layer, in average closer to the observations. The sloping-down of the layers with along-track distance (East to West) is well-captured by both models. Again, however, the individual plume at an along-track distance of $1260 \mathrm{~km}$ is not captured in either model, and neither is the co-located elevated plume. This is 

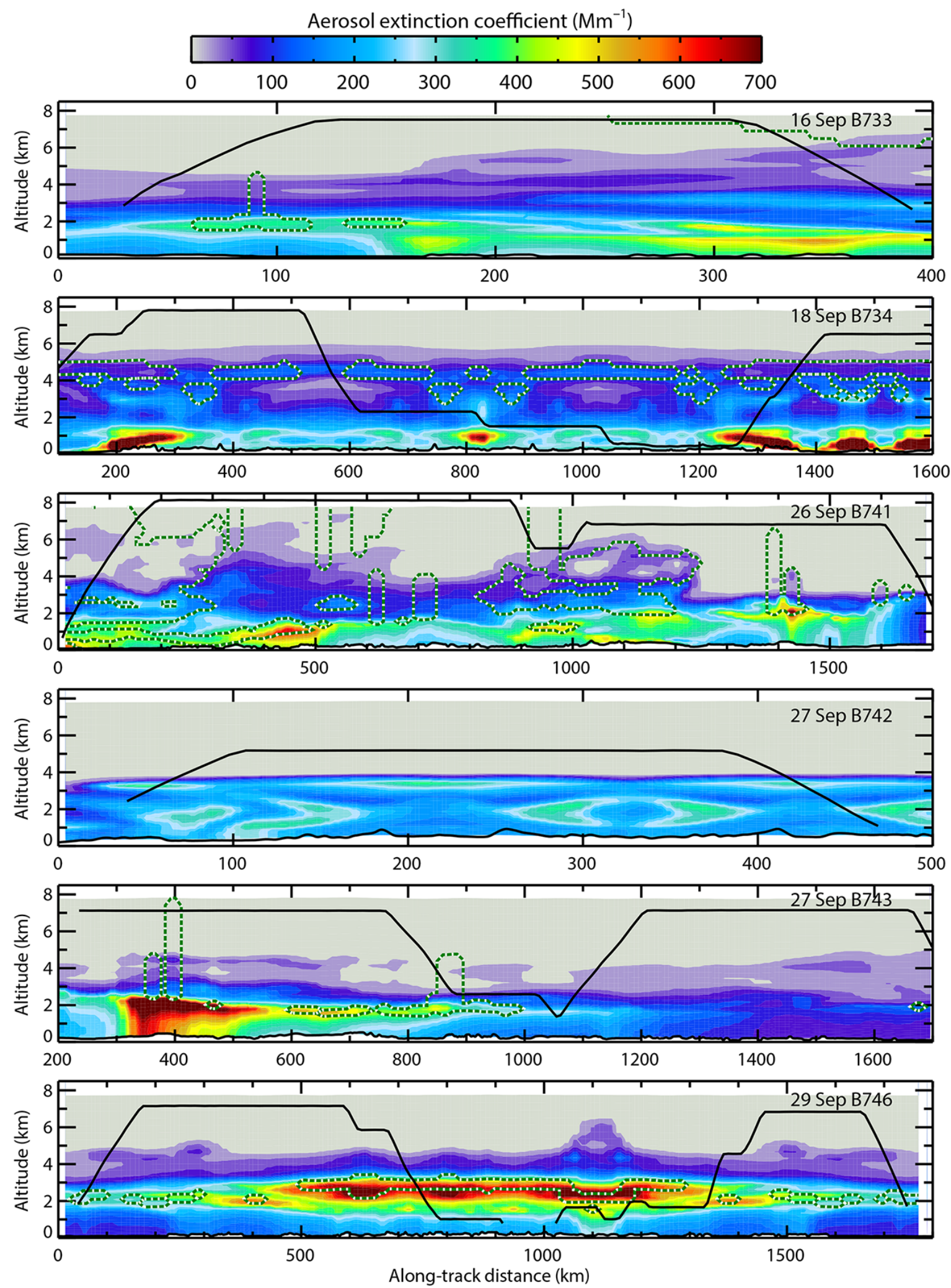

Figure 10. Cross-sections of the aerosol extinction coefficient estimated from the Met Office Unified Model (MetUM) along the tracks of the six research flights. Also shown is the position of the model clouds (green dotted line). 

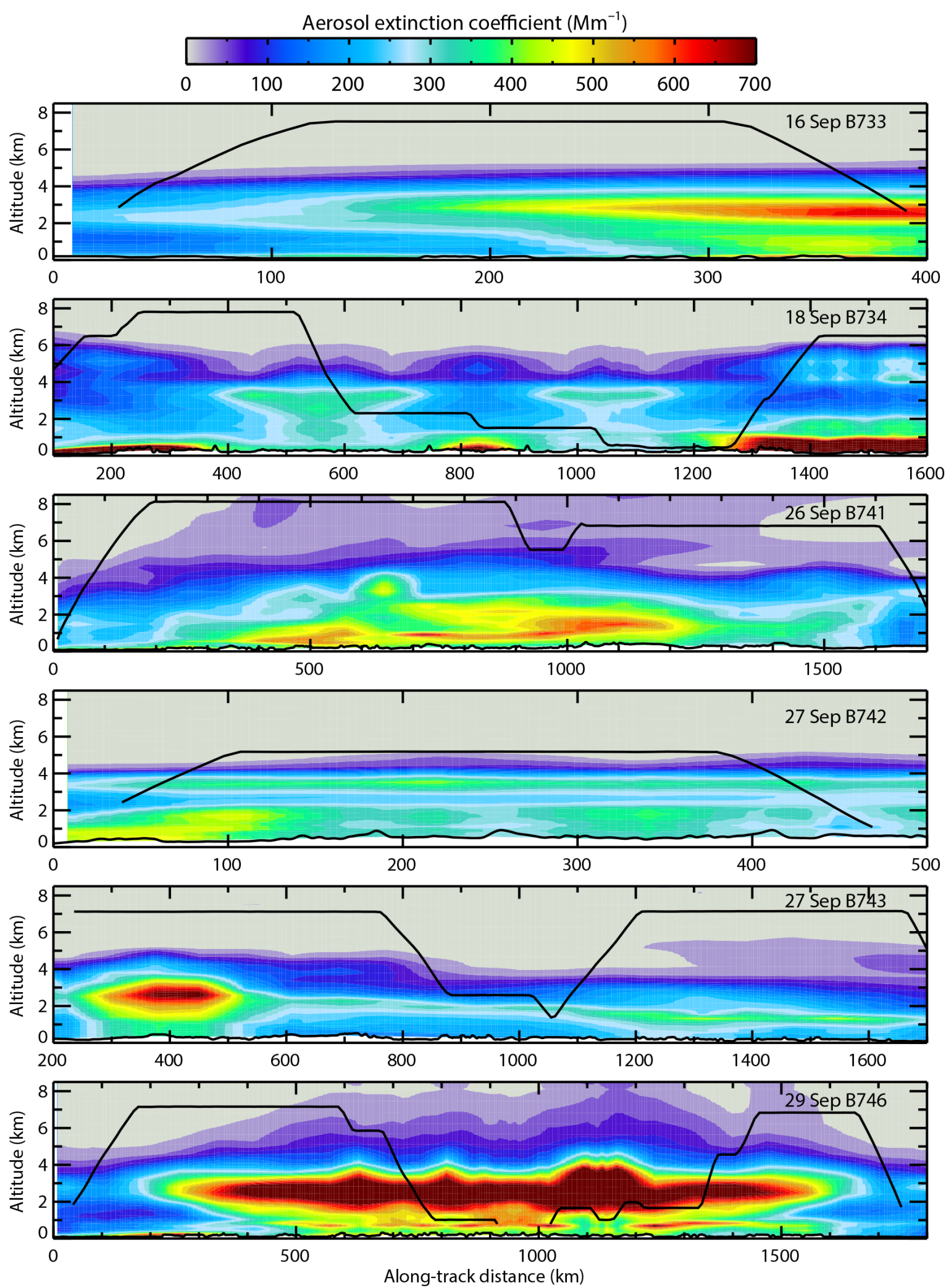

Figure 11. Cross-sections of the aerosol extinction coefficient estimated from the ECMWF-MACC model, along the tracks of the six research flights. 
not surprising, as the fire was not captured in the GFAS inventory.

Finally, for B746 the overall structure and magnitude of the smoke layer observed by the lidar is surprisingly well represented in both models, with the exception of the very large values of extinction found just above the low-level clouds.

Some of the largest discrepancies between the models and the observations occur in regions affected by clouds; for instance during B741 (first part, Sect. 4) and B746 (large extinction values above and near the clouds). This may be due to differences in location between modelled and observed convection (and associated transport and/or wet deposition of aerosol), or to errors in the water uptake of aerosols near to, or within clouds. This should not be considered surprising, as these processes are difficult to model accurately, and still not well understood.

The blue and red lines in Figs. 8 and 9 show the MetUM and ECMWF-MACC mean and standard deviation, for each flight section and for the campaign average profile. These vertical profiles confirm the above conclusions; it is interesting, in any case, to observe the similarity of the campaign average profile derived with the lidar and the MetUM (Fig. 9). Although the MetUM average does not seem to capture the transition between the first shallow layer (up to $\sim 1 \mathrm{~km}$ ) and the elevated layer between $\sim 1$ and $\sim 5 \mathrm{~km}$, such an elevated layer is shown clearly in most of the profiles in Fig. 8 (flight sections $1,3,5$, and 7-10), but by averaging over multiple profiles with opposite structures (e.g. section 4) this is not apparent. Note also the structure of the campaign mean ECMWF-MACC profile, with a nearly constant extinction coefficient from the surface to $3 \mathrm{~km}$, followed by a decrease until the top of the layer at $\sim 6 \mathrm{~km}$. Again, this results from averaging profiles with opposite structures, i.e. sections 2, 3 and 4 , showing very large concentrations near the surface, and sections 1 , and 5-10 that show larger extinction in the elevated layer. It is also clear from the averaged profiles that the ECMWF-MACC model shows larger aerosol extinction than the lidar and the MetUM, and that the simulated layers extend slightly further in the vertical.

Finally, Fig. 12 shows the hotspots reported in GFAS during the campaign, coloured according to the injection height computed in the PRM. We can see that several fires with injection height between 3 and $5 \mathrm{~km}$ are observed, particularly in the eastern (upwind) part of the basin, and this is where the smoke can have been generated. Moreover, sporadic fires with very large injection heights $(5-7 \mathrm{~km})$ are observed between 50 and $65^{\circ} \mathrm{W}$. The smoke layer depths observed by lidar and predicted by the models are therefore generally compatible with the PRM injection heights.

\section{Summary and conclusions}

Research flights in Brazil, during SAMBBA (dry season of 2012), offered an opportunity to map the vertical structure

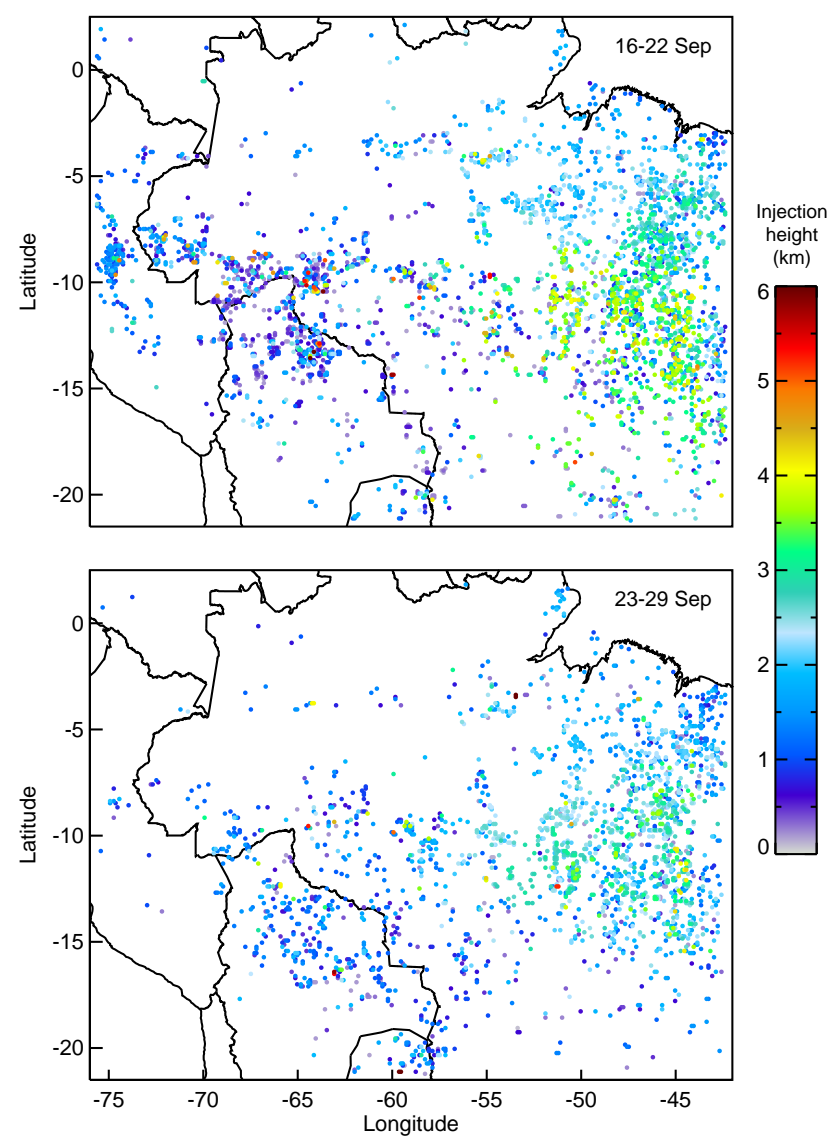

Figure 12. Hotspots during 16-22 September (top) and 2329 September (bottom), as reported in the GFAS inventory. Each hotspot is coloured according to the corresponding injection height computed by the plume rise model embedded in GFAS.

of the Amazonian haze using airborne lidar. The sampling region extended $\sim 2200 \mathrm{~km}$ along an east-west direction, centred around a mean latitude of $10^{\circ} \mathrm{S}$, and the sampling period was 14-days long. Lidar profiles underwent cloud screening and a series of quality tests, including a manual profile-by-profile review of the reference height interval and cloud screening. High loadings of biomass burning aerosol were present, with an average AOD of $0.65 \pm 0.24$ and a layer extinction (vertically averaged aerosol extinction) of $112 \pm 49 \mathrm{Mm}^{-1}$. Within the main aerosol layers, the extinction was often much larger than this, and ranged 100$400 \mathrm{Mm}^{-1}$ typically, and reaching values as high as 1000$1500 \mathrm{Mm}^{-1}$ locally.

The lidar generally showed a vertical structure of the atmosphere consisting of an aerosol layer from the surface to an altitude of $1-1.5 \mathrm{~km}$; and elevated aerosols above and up to $4-6 \mathrm{~km}$, usually representing the major portion of the airborne smoke. This structure may be indicative of a divide between fresher smoke near the surface and more aged aerosol higher up. The elevated aerosols were sometimes found in the form of a single well-defined layer, whereas at other times 
multiple layers were observed. On average, across the data set considered here the layer height was $2.0 \pm 0.4 \mathrm{~km}$ and the layer depth was $2.3 \pm 0.6 \mathrm{~km}$ (mean and standard deviation). This general structure is likely to be a consequence of dynamical processes, such as initial plume-rise, vertical transport by dry and moist convection, and large-scale motion. Lifting of the aerosols from the surface can be explained with fire radiative power; see e.g. the plumes in B743, at an along-track distance of $1260 \mathrm{~km}$, where lifting up to $2-3 \mathrm{~km}$ is evident, with an additional plume at $\sim 4 \mathrm{~km}$. In this respect, the injection heights computed in the PRM (Fig. 12), display a general consistency with the plume depths reported in the present study. Considering the large number of convective clouds encountered during SAMBBA (mainly in the western half of the area sampled), updrafts in cumulus and cumulonimbus can also be ascribed as a mechanism for lifting smoke above the boundary layer.

The mean vertical distribution of the aerosols that we observed is not too dissimilar to the results of other studies, such as Baars et al. (2012, Figs. 5 and 14), Huang et al. (2015, Fig. 6a and b), and Bourgeois et al. (2015, Fig. 6e); note, however, than in the latter paper the aerosols were found to be mainly in the boundary layer, below $2-2.5 \mathrm{~km}$. The general vertical structure that we have found was fairly consistent across the region sampled (which extended $\sim 2200 \mathrm{~km}$ in an East-West direction) and across the time period considered (14 days). As an exception to this, very large aerosol loads were found (extinction $1000-1500 \mathrm{Mm}^{-1}$ and AOD 11.8) in two circumstances: (i) in individual fire plumes, and (ii) in the vicinity of clouds. The latter circumstance suggests either the uptake of water by aerosol close to clouds (Koren et al., 2007), or that smoke has been transported vertically within convective clouds and detrained to form elevated layers with locally high aerosol extinction coefficient.

An evaluation of the biomass burning lidar ratio has also been completed, using the lidar profiles themselves. Consistency of the observed profiles with Rayleigh scattering above the aerosol layers permitted the lidar ratio to be estimated as $73 \pm 6$ sr. This estimate has been compared with Mie scattering calculations using the campaign mean size-distribution obtained from wing-mounted optical particle counters. It has been found that the computed lidar ratio is very dependent upon the refractive index, and indeed the observed value is compatible with values of the real and imaginary parts published in the literature.

The present research effort has been a good opportunity for a general test of the Marenco (2013) inversion method, and it represents its first application to a large number of lidar profiles. This method is a variant of the traditional FernaldKlett approach, where a far-range reference is taken within an aerosol layer instead of in a Rayleigh scattering portion of the atmosphere (the latter being only available at nearrange, leading to retrieval instabilities). The method is suitable for the observation of deep and optically thick layers, when observed in a nadir-viewing geometry. A profile-by- profile evaluation of the uncertainties introduced by the inversion assumptions has been included. These uncertainties are shown in Fig. 6 and can approach values as large as 50$100 \%$ near the surface, but they are much reduced at altitudes larger than $1-2 \mathrm{~km}$.

The observed structure of the aerosol layer has been compared to predictions with a limited-area configuration of the MetUM and with the ECMWF-MACC global model. In most cases, the models represented the general vertical structure of the aerosol layers and showed realistic features, such as layer depth and magnitude of the extinction coefficient. For instance, in many cases the models showed a similar aerosol layer depth, and a similar magnitude of the extinction coefficient, although some differences exist, and the exact position of features was not always exactly reproduced. Certain features, such as individual fire plumes and high extinction values in the vicinity of clouds, were however not well captured.

We believe that it is important to highlight the strengths and weaknesses of the models in predicting the vertical structure, because the latter is usually considered a weak point. It is to be noted that the MetUM SAMBBA LAM was set up specifically to support the field campaign, and its primary purpose was to facilitate flight planning, whereas the purpose of the ECMWF-MACC simulations is somewhat different. The latter is an operational global composition model, with forecast charts made available publicly on the web on a daily basis, and for which specially zoomed charts can be requested for campaign support. In both cases, the simulations are judged to be useful if they provide some skill in predicting the typical vertical distribution of the aerosol, the regional distribution, and the day-to-day variability of aerosol loadings. Our results show some skill in simulating these aspects, even if the fine detail is not always captured, and we conclude that the simulations have served their purpose well.

The MetUM LAM simulations were a first attempt at generating forecasts of biomass burning aerosols with the CLASSIC prognostic aerosol scheme, and provided an opportunity to test this potential advance in the Met Office's operational atmospheric composition modelling capability. The present paper therefore addresses the benefits of the prognostic treatment of biomass burning aerosols offer over an aerosol climatology, and the fact that regional and vertical variations can be predicted with some skill is very satisfying. Aerosol schemes can be sensitive to the host atmospheric model and its configuration (grid-resolution, dynamics, processes) and to the scheme's assumptions. An evaluation of the CLASSIC scheme with detailed observations is important, as it highlights whether the simulated spatial patterns can be considered realistic when run at high resolution. Some aspects of the LAM aerosol simulations during SAMBBA were also evaluated by Kolusu et al. (2015), and showed that the regional distribution and magnitude of AOD agrees well with observations. The current study adds the evaluation of the vertical profile to this assessment, and moreover gives an 
indication that the emission scaling factors used (1.7 for the MetUM and 3.4 for ECMWF-MACC) is reasonable.

Kolusu et al. (2015) have also investigated the impact of the prognostic biomass burning aerosols on the meteorology simulated with the MetUM. They have found an impact on the radiation balance, improvements in forecasts of temperature and humidity, and they have highlighted important changes in the representation of the regional hydrological cycle. In this respect, we believe that the vertical profile of the aerosols is a key variable to take into account, and that our data set can prove precious for such studies.

In the ECMWF-MACC model, injection heights are simulated interactively from the PRM, and this led to some improvements in the vertical profile of aerosol for flights B741, B742 and B746. A separate paper on this topic is in preparation (Rémy et al., 2015), and therein it will be shown that, e.g., for flight B742 the simulation using the PRM is able to predict the two distinct smoke layers that were observed, whereas only one broader layer is predicted if the PRM is not used.

In conclusion, the airborne lidar has once again proven to be a powerful tool for mapping aerosols along the vertical and horizontal axes. The ability to vertically profile the atmosphere yields an advantage over passive remote sensing, in that the atmospheric structure can be resolved, and moreover the observed signal is not sensitive to parameters such as layer temperature and ground reflection or emission. Lidar permits sampling of the whole atmospheric column, and thus to retrieve a complete picture of the atmospheric structure, and is thus complementary to in situ techniques that can yield more detailed microphysical information but on a smaller spatial scale. We believe that our study also illustrates well the application of lidar observations to model verification and assessment, and it opens the door to a series of further studies: besides the above-mentioned evaluation of the GFAS inventory (Rémy et al., 2015), we are also working on an evaluation of the UKCA-MODE aerosol scheme in the Met Office climate model (Johnson et al., 2016).

Acknowledgements. Airborne data were obtained using the BAe-146-301 Atmospheric Research Aircraft (ARA) flown by Directflight Ltd and managed by the Facility for Airborne Atmospheric Measurements (FAAM), which is a joint entity of the Natural Environment Research Council (NERC) and the Met Office. SAMBBA was funded by the Met Office and NERC (grant NE/J009822/1). Patrick Chazette and the Commissariat à l'Energie Atomique et aux Energies Alternatives (CEA) are kindly thanked for help fixing our lidar prior to SAMBBA.

Edited by: S. Martin

\section{References}

Abel, S. J., Haywood, J. M., Highwood, E. J., Li, J., and Buseck, P. R.: Evolution of biomass burning aerosol properties from an agricultural fire in southern Africa, Geophys. Res. Lett., 30, 1783, doi:10.1029/2003GL017342, 2003.

Allen, G., Illingworth, S. M., O'Shea, S. J., Newman, S., Vance, A., Bauguitte, S. J.-B., Marenco, F., Kent, J., Bower, K., Gallagher, M. W., Muller, J., Percival, C. J., Harlow, C., Lee, J., and Taylor, J. P.: Atmospheric composition and thermodynamic retrievals from the ARIES airborne TIR-FTS system - Part 2: Validation and results from aircraft campaigns, Atmos. Meas. Tech., 7, 4401-4416, doi:10.5194/amt-7-4401-2014, 2014.

Andreae, M. O., Rosenfeld, D., Artaxo, P., Costa, A. A., Frank, G. P., Longo, K. M., and Silva-Dias, M. A. F.: Smoking Rain Clouds over the Amazon, Science, 303, 1337-1342, 2004.

Angelo, C.: Amazon fire analysis hits new heights, Nature News, doi:10.1038/nature.2012.11467, 2012.

Baars, H., Ansmann, A., Althausen, D., Engelmann, R., Heese, B., Müller, D., Artaxo, P., Paixao, M., Pauliquevis, T., and Souza, R.: Aerosol profiling with lidar in the Amazon Basin during the wet and dry season, J. Geophys. Res., 117, D21201, doi:10.1029/2012JD018338, 2012.

Bellouin, N., Rae, J., Jones, A., Johnson, C., Haywood, J., and Boucher, O.: Aerosol forcing in the Climate Model Intercomparison Project (CMIP5) simulations by HadGEM2-ES and the role of ammonium nitrate, J. Geophys. Res., 116, D20206, doi:10.1029/2011JD016074, 2011.

Benedetti, A., Morcrette, J.-J., Boucher, O., Dethof, A., Engelen, R. J., Fisher, M., Flentje, H., Huneeus, N., Jones, L., Kaiser, J. W., Kinne, S., Mangold, A., Razinger, M., Simmons, A. J., and Suttie, M.: , Aerosol analysis and forecast in the European Centre for Medium-Range Weather Forecasts Integrated Forecast System: 2. Data assimilation, J. Geophys. Res., 114, D13205, doi:10.1029/2008JD011115, 2009.

Boucher, O., Pham, M., and Venkataraman, C.: Simulation of the atmospheric sulfur cycle in the Laboratoire de Meteorologie Dynamique general circulation model: Model description, model evaluation, and global and European budgets, Institut Pierre Simon Laplace (Note Sci. IPSL 23), Paris, France, 2002.

Bourgeois, Q., Ekman, A. M. L., and Krejci, R.: Aerosol transport over the Andes from the Amazon Basin to the remote Pacific Ocean: A multiyear CALIOP assessment, J. Geophys. Res., 120, 8411-8425, 2015.

Brito, J., Rizzo, L. V., Morgan, W. T., Coe, H., Johnson, B., Haywood, J., Longo, K., Freitas, S., Andreae, M. O., and Artaxo, P. Ground-based aerosol characterization during the South American Biomass Burning Analysis (SAMBBA) field experiment, Atmos. Chem. Phys., 14, 12069-12083, doi:10.5194/acp-1412069-2014, 2014.

Chand, D., Anderson, T. L., Wood, R., Charlson, R. J., Hu, Y., Liu, Z., and Vaughan, M.: Quantifying above-cloud aerosol using spaceborne lidar for improved understanding of cloudysky direct climate forcing, J. Geophys. Res., 113, D13206, doi:10.1029/2007JD009433, 2008.

Chazette, P., Dabas, A., Sanak, J., Lardier, M., and Royer, P.: French airborne lidar measurements for Eyjafjallajökull ash plume survey, Atmos. Chem. Phys., 12, 7059-7072, doi:10.5194/acp-127059-2012, 2012. 
Dubovik, O., Holben, B., Eck, T. F., Smirnov, A., Kaufman, Y. J., King, M. D., Tanré, D., and Slutsker, I.: Variability of absorption and optical properties of key aerosol types observed in worldwide locations, J. Atmos. Sci., 59, 590-608, 2002.

Fernald, F. G.: Analysis of atmospheric lidar observations: some comments, Appl. Opt., 23, 652-653, 1984.

Fiebig, M., Stohl, A., Wendisch, M., Eckhardt, S., and Petzold, A.: Dependence of solar radiative forcing of forest fire aerosol on ageing and state of mixture, Atmos. Chem. Phys., 3, 881-891, doi:10.5194/acp-3-881-2003, 2003.

Freitas, S. R., Longo, K. M., Chatfield, R., Latham, D., Silva Dias, M. A. F., Andreae, M. O., Prins, E., Santos, J. C., Gielow, R., and Carvalho Jr., J. A.: Including the sub-grid scale plume rise of vegetation fires in low resolution atmospheric transport models, Atmos. Chem. Phys., 7, 3385-3398, doi:10.5194/acp-7-3385-2007, 2007.

Gerbig, C., Kley, D., Volz-Thomas, A., Kent, J., Dewey, K., and McKenna, D. S.: Fast response resonance fluorescence CO measurements aboard the C-130: Instrument characterization and measurements made during North Atlantic Regional Experiment 1993, J. Geophys. Res., 101, 29229-29238, 1996.

Gerbig, C., Schmitgen, S., Kley, D., Volz-Thomas, A., Dewey, K., and Haaks, D.: An improved fast-response vacuum-UV resonance fluorescence CO instrument, J. Geophys. Res., 104, 16991704, 1999.

Gonçalves, W. A., Machado, L. A. T., and Kirstetter, P.-E.: Influence of biomass aerosol on precipitation over the Central Amazon: an observational study, Atmos. Chem. Phys., 15, 6789-6800, doi:10.5194/acp-15-6789-2015, 2015.

Groß, S., Freudenthaler, V., Wiegner, M., Gasteiger, J., Geiß, A., and Schnell, F.: Dual-wavelength linear depolarization ratio of volcanic aerosols: Lidar measurements of the Eyjafjallajökull plume over Maisach, Germany, Atmos. Environ., 48, 85-96, 2012

Guyon, P., Graham, B., Beck, J., Boucher, O., Gerasopoulos, E., Mayol-Bracero, O. L., Roberts, G. C., Artaxo, P., and Andreae, M. O.: Physical properties and concentration of aerosol particles over the Amazon tropical forest during background and biomass burning conditions, Atmos. Chem. Phys., 3, 951-967, doi:10.5194/acp-3-951-2003, 2003.

Haywood, J. M., Osborne, S. R., Francis, P. N., Keil, A., Formenti, P., Andreae, M. O., and Kaye, P. H.: The mean physical and optical properties of regional haze dominated by biomass burning aerosol measured from the C-130 aircraft during SAFARI 2000, J. Geophys. Res., 108, 8473, doi:10.1029/2002JD002226, 2003.

Hobbs, P. V., Reid, J. S., Kotchenruther, R. A., Ferek, R. J., and Weiss, R.: Direct radiative forcing by smoke from biomass burning, Science, 275, 1777-1778, 1997.

Huang, J., Guo, J., Wang, F., Liu, Z., Jeong, M.-J., Yu, H., and Zhang, Z.: CALIPSO inferred most probable heights of global dust and smoke layers, J. Geophys. Res., 120, 5085-5100, 2015.

Johnson, B., Haywood, J., Langridge, J., Darbyshire, E., Morgan, W., Szpeck, K., Brooke, J., Marenco, F., Coe, H., Artaxo, P., Longo, K., Mulcahy, J., Mann, G., Dalvi, M., and Bellouin, N.: Evaluation of biomass burning aerosols in the HadGEM3 climate model with observations from SAMBBA, Atmos. Chem. Phys. Discuss., in preparation, 2016.
Kaiser, J. W., Heil, A., Andreae, M. O., Benedetti, A., Chubarova, N., Jones, L., Morcrette, J.-J., Razinger, M., Schultz, M. G., Suttie, M., and van der Werf, G. R.: Biomass burning emissions estimated with a global fire assimilation system based on observed fire radiative power, Biogeosciences, 9, 527-554, doi:10.5194/bg-9-527-2012, 2012.

Kaufman, Y. J., Hobbs, P. V., Kirchhoff, V. W. J. H., Artaxo, P., Remer, L. A., Holben, B. N., King, M. D., Ward, D. E., Prins, E. M., Longo, K. M., Mattos, L. F., Nobre, C. A., Spinhirne, J. D., Ji, Q., Thompson, A. M., Gleason, J. F., Christopher, S. A., and Tsay, S.-C.: Smoke, Clouds, and Radiation-Brazil (SCAR-B) experiment, J. Geophys. Res., 103, 31783-31808, 1998.

Klett, J. D.: Lidar inversion with variable backscatter/extinction ratios, Appl. Opt., 24, 1638-1643, 1985.

Kolusu, S. R., Marsham, J. H., Mulcahy, J., Johnson, B., Dunning, C., Bush, M., and Spracklen, D. V.: Impacts of Amazonia biomass burning aerosols assessed from short-range weather forecasts, Atmos. Chem. Phys., 15, 12251-12266, doi:10.5194/acp-15-12251-2015, 2015.

Koppmann, R., von Czapiewski, K., and Reid, J. S.: A review of biomass burning emissions, part I: gaseous emissions of carbon monoxide, methane, volatile organic compounds, and nitrogen containing compounds, Atmos. Chem. Phys. Discuss., 5, 10455 10516, doi:10.5194/acpd-5-10455-2005, 2005.

Koren, I., Remer, L. A., Kaufman, Y. J., Rudich, Y., and Martins, J. V.: On the twilight zone between clouds and aerosols, Geophys. Res. Lett., 34, L08805, doi:10.1029/2007GL029253, 2007.

Koren, I., Martins, J. V., Remer, L. A., and Afargan, H.: Smoke Invigoration Versus Inhibition of Clouds over the Amazon, Science, 321, 946-949, 2008.

Labonne, M., Breon, F.-M., and Chevallier, F.: Injection height of biomass burning aerosols as seen from a spaceborne lidar, Geophys. Res. Lett., 34, L11806, doi:10.1029/2007GL029311, 2007.

Lance, S., Brock, C. A., Rogers, D., and Gordon, J. A.: Water droplet calibration of the Cloud Droplet Probe (CDP) and inflight performance in liquid, ice and mixed-phase clouds during ARCPAC, Atmos. Meas. Tech., 3, 1683-1706, doi:10.5194/amt3-1683-2010, 2010.

Liu, P. S. K., Leaitch, W. R., Strapp, J. W., and Wasey, M. A.: Response of particle measuring systems airborne ASASP and PCASP to $\mathrm{NaCl}$ and latex particles, Aerosol Sci. Tech., 16, 8395, 1992.

Lolli, S., Sauvage, L., Loaec, S., and Lardier, M.: EZ Lidar(TM): A new compact autonomous eye-safe scanning aerosol lidar for extinction measurements and PBL height detection. Validation of the performances against other instruments and intercomparison campaigns, Óptica Pura y Aplicada, 44, 33-41, 2011.

Lopes, F. J. S., Landulfo, E., and Vaughan, M. A.: Evaluating CALIPSO's $532 \mathrm{~nm}$ lidar ratio selection algorithm using AERONET sun photometers in Brazil, Atmos. Meas. Tech., 6, 3281-3299, doi:10.5194/amt-6-3281-2013, 2013.

Magi, B. and Hobbs, P. V.: Effects of humidity on aerosols and southern Africa during the biomass burning season, J. Geophys. Res., 108, 8495, doi:10.1029/2002JD002144, 2003.

Marenco, F.: Nadir airborne lidar observations of deep aerosol layers, Atmos. Meas. Tech., 6, 2055-2064, doi:10.5194/amt-62055-2013, 2013. 
Marenco, F., Johnson, B., Turnbull, K., Newman, S., Haywood, J., Webster, H., and Ricketts, H.: Airborne Lidar Observations of the 2010 Eyjafjallajökull Volcanic Ash Plume, J. Geophys. Res., 116, D00U05, doi:10.1029/2011JD016396, 2011.

Marenco, F., Amiridis, V., Marinou, E., Tsekeri, A., and Pelon, J.: Airborne verification of CALIPSO products over the Amazon: a case study of daytime observations in a complex atmospheric scene, Atmos. Chem. Phys., 14, 11871-11881, doi:10.5194/acp14-11871-2014, 2014.

Mattis, I., Ansmann, A., Wandinger, U., and Müller, D.: Unexpectedly high aerosol load in the free troposphere over central Europe in spring/summer 2003, Geophys. Res. Lett., 30, 2178, doi:10.1029/2003GL018442, 2003.

Mercado, L. M., Bellouin, N., Sitch, S., Boucher, O., Huntingford, C., Wild, M., and Cox, P. M.: Impact of changes in diffuse radiation on the global land carbon sink, Nature, 458, 1014-1017, 2009.

Morcrette, J.-J., Boucher, O., Jones, L., Salmond, D., Bechtold, P., Beljaars, A., Benedetti, A., Bonet, A., Kaiser, J. W., Razinger, M., Schulz, M., Serrar, S., Simmons, A. J., Sofiev, M., Suttie, M., Tompkins, A. M., and Untch, A.: Aerosol analysis and forecast in the European Centre for Medium-Range Weather Forecasts Integrated Forecast System: Forward modeling, J. Geophys. Res., 114, D06206, doi:10.1029/2008JD011235, 2009.

Müller, D., Mattis, I., Wandinger, U., Ansmann, A., Althausen, D., and Stohl, A.: Raman lidar observations of aged Siberian and Canadian forest fire smoke in the free troposphere over Germany in 2003: Microphysical particle characterization, J. Geophys. Res., 110, D17201, doi:10.1029/2004JD005756, 2005.

Omar, A. H., Winker, D. M., Kittaka, C., Vaughan, M. A., Liu, Z., Hu, Y., Trepte, C. R., Rogers, R. R., Ferrare, R. A., Lee, K.-P., Kuehn, R. E., and Hostetler, C. A.: The CALIPSO Automated Aerosol Classification and Lidar Ratio Selection Algorithm, J. Atmos. Ocean. Tech., 26, 1994-2014, 2009.

Palmer, P. I., Parrington, M., Lee, J. D., Lewis, A. C., Rickard, A. R., Bernath, P. F., Duck, T. J., Waugh, D. L., Tarasick, D. W., Andrews, S., Aruffo, E., Bailey, L. J., Barrett, E., Bauguitte, S. J.-B., Curry, K. R., Di Carlo, P., Chisholm, L., Dan, L., Forster, G., Franklin, J. E., Gibson, M. D., Griffin, D., Helmig, D., Hopkins, J. R., Hopper, J. T., Jenkin, M. E., Kindred, D., Kliever, J., Le Breton, M., Matthiesen, S., Maurice, M., Moller, S., Moore, D. P., Oram, D. E., O'Shea, S. J., Owen, R. C., Pagniello, C. M. L. S., Pawson, S., Percival, C. J., Pierce, J. R., Punjabi, S., Purvis, R. M., Remedios, J. J., Rotermund, K. M., Sakamoto, K. M., da Silva, A. M., Strawbridge, K. B., Strong, K., Taylor, J., Trigwell, R., Tereszchuk, K. A., Walker, K. A., Weaver, D., Whaley, C., and Young, J. C.: Quantifying the impact of BOReal forest fires on Tropospheric oxidants over the Atlantic using Aircraft and Satellites (BORTAS) experiment: design, execution and science overview, Atmos. Chem. Phys., 13, 6239-6261, doi:10.5194/acp-13-6239-2013, 2013.

Paugam, R., Wooster, M., Atherton, J., Freitas, S. R., Schultz, M. G., and Kaiser, J. W.: Development and optimization of a wildfire plume rise model based on remote sensing data inputs - Part 2, Atmos. Chem. Phys. Discuss., 15, 9815-9895, doi:10.5194/acpd-15-9815-2015, 2015.

Reddy, M. S., Boucher, O., Bellouin, N., Schulz, M., Balkanski, Y., Dufresne, J.-L., and Pham, M.: Estimates of global multicomponent aerosol optical depth and direct radiative perturbation in the Laboratoire de Meteorologie Dynamique general circulation model, J. Geophys. Res., 110, D10S16, doi:10.1029/2004JD004757, 2005.

Reid, J. S. and Hobbs, P. V.: Physical and optical properties of young smoke from individual biomass fires in Brazil, J. Geophys. Res., 103, 32013-32030, 1998.

Reid, J. S., Eck, T. F., Christopher, S. A., Koppmann, R., Dubovik, O., Eleuterio, D. P., Holben, B. N., Reid, E. A., and Zhang, J.: A review of biomass burning emissions part III: intensive optical properties of biomass burning particles, Atmos. Chem. Phys., 5, 827-849, doi:10.5194/acp-5-827-2005, 2005a.

Reid, J. S., Koppmann, R., Eck, T. F., and Eleuterio, D. P.: A review of biomass burning emissions part II: intensive physical properties of biomass burning particles, Atmos. Chem. Phys., 5, 799825, doi:10.5194/acp-5-799-2005, 2005b.

Rémy, S., Veira, A., Paugam, R., Kaiser, J., Marenco, F., Burton, S., Benedetti, A., Engelen, R., Ferrare, R., and Hair, J.: Two global climatologies of daily fire emission injection heights since 2003, Atmos. Chem. Phys., submitted, 2015.

Rizzo, L. V., Artaxo, P., Müller, T., Wiedensohler, A., Paixão, M., Cirino, G. G., Arana, A., Swietlicki, E., Roldin, P., Fors, E. O., Wiedemann, K. T., Leal, L. S. M., and Kulmala, M.: Long term measurements of aerosol optical properties at a primary forest site in Amazonia, Atmos. Chem. Phys., 13, 2391-2413, doi:10.5194/acp-13-2391-2013, 2013.

Rosenberg, P. D., Dean, A. R., Williams, P. I., Dorsey, J. R., Minikin, A., Pickering, M. A., and Petzold, A.: Particle sizing calibration with refractive index correction for light scattering optical particle counters and impacts upon PCASP and CDP data collected during the Fennec campaign, Atmos. Meas. Tech., 5, 1147-1163, doi:10.5194/amt-5-1147-2012, 2012.

Ryder, C. L., Highwood, E. J., Rosenberg, P. D., Trembath, J., Brooke, J. K., Bart, M., Dean, A., Crosier, J., Dorsey, J., Brindley, H., Banks, J., Marsham, J. H., McQuaid, J. B., Sodemann, H., and Washington, R.: Optical properties of Saharan dust aerosol and contribution from the coarse mode as measured during the Fennec 2011 aircraft campaign, Atmos. Chem. Phys., 13, $303-$ 325, doi:10.5194/acp-13-303-2013, 2013.

Seifert, P., Kunz, C., Baars, H., Ansmann, A., Bühl, J., Senf, F., Engelmann, R., Althausen, D., and Artaxo, P.: Seasonal variability of heterogeneous ice formation in stratiform clouds over the Amazon Basin, Geophys. Res. Lett., 42, 5587-5593, 2015.

Sena, E. T., Artaxo, P., and Correia, A. L.: Spatial variability of the direct radiative forcing of biomass burning aerosols and the effects of land use change in Amazonia, Atmos. Chem. Phys., 13, 1261-1275, doi:10.5194/acp-13-1261-2013, 2013.

Sofiev, M., Ermakova, T., and Vankevich, R.: Evaluation of the smoke-injection height from wild-land fires using remote-sensing data, Atmos. Chem. Phys., 12, 1995-2006, doi:10.5194/acp-12-1995-2012, 2012.

Stocker, T. F., Qin, D., Plattner, G.-K., Tignor, M. M., Allen, S. K., Boschung, J., Nauels, A., Xia, Y., Bex, V., and Midgley, P. M.: Climate change 2013: The physical science basis, unedited online version, available at: www.ipcc.ch/report/ar5/wg1/ (last access: 19 February 2016), 2013.

Textor, C., Schulz, M., Guibert, S., Kinne, S., Balkanski, Y., Bauer, S., Berntsen, T., Berglen, T., Boucher, O., Chin, M., Dentener, F., Diehl, T., Easter, R., Feichter, H., Fillmore, D., Ghan, S., Ginoux, P., Gong, S., Grini, A., Hendricks, J., Horowitz, L., Huang, P., 
Isaksen, I., Iversen, I., Kloster, S., Koch, D., Kirkevåg, A., Kristjansson, J. E., Krol, M., Lauer, A., Lamarque, J. F., Liu, X., Montanaro, V., Myhre, G., Penner, J., Pitari, G., Reddy, S., Seland, Ø., Stier, P., Takemura, T., and Tie, X.: Analysis and quantification of the diversities of aerosol life cycles within AeroCom, Atmos. Chem. Phys., 6, 1777-1813, doi:10.5194/acp-6-1777-2006, 2006.

Vakkari, V., Kerminen, V.-M., Beukes, J. P., Tiitta, P., van Zyl, P. G., Josipovic, M., Venter, A. D., Jaars, K., Worsnop, D. R., Kulmala, M., and Laakso, L.: Rapid changes in biomass burning aerosols by atmospheric oxidation, Geophys. Res. Lett., 41, 2644-2651, 2014.
Walters, D. N., Best, M. J., Bushell, A. C., Copsey, D., Edwards, J. M., Falloon, P. D., Harris, C. M., Lock, A. P., Manners, J. C., Morcrette, C. J., Roberts, M. J., Stratton, R. A., Webster, S., Wilkinson, J. M., Willett, M. R., Boutle, I. A., Earnshaw, P. D., Hill, P. G., MacLachlan, C., Martin, G. M., Moufouma-Okia, W., Palmer, M. D., Petch, J. C., Rooney, G. G., Scaife, A. A., and Williams, K. D.: The Met Office Unified Model Global Atmosphere 3.0/3.1 and JULES Global Land 3.0/3.1 configurations, Geosci. Model Dev., 4, 919-941, doi:10.5194/gmd-4-919-2011, 2011. 